INEEL/EXT/99-00650

BECEIVEO

DEC 272020

OSTI

\title{
Field Operations Program \\ Chevrolet S-10 (Lead-Acid) Accelerated Reliability Testing - Final Report
}

\author{
J. Francfort ${ }^{1}$ \\ J. Argueta ${ }^{2}$ \\ M. Wehrey ${ }^{2}$ \\ D. Karner ${ }^{3}$ \\ L. Tyree ${ }^{3}$
}

Published July 1999

Idaho National Engineering and Environmental Laboratory Automotive Systems and Technology Department Idaho Falls, Idaho 83415

\author{
Prepared for the \\ U.S. Department of Energy \\ Assistant Secretary for Energy Efficiency and Renewable Energy \\ Under DOE Idaho Operations Office \\ Contract No. DE-AC07-94ID13223
}

\footnotetext{
TINEEL/Lockheed Martin Idaho Technologies Co.

2 Southern California Edison

${ }^{3}$ Electric Transportation Applications
} 


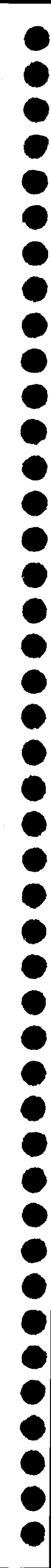




\section{DISCLAIMER}

This report was prepared as an account of work sponsored by an agency of the United States Government. Neither the United States Government nor any agency thereof, nor any of their employees, make any warranty, express or implied, or assumes any legal liability or responsibility for the accuracy, completeness, or usefulness of any information, apparatus, product, or process disclosed, or represents that its use would not infringe privately owned rights. Reference herein to any specific commercial product, process, or service by trade name, trademark, manufacturer, or otherwise does not necessarily constitute or imply its endorsement, recommendation, or favoring by the United States Government or any agency thereof. The views and opinions of authors expressed herein do not necessarily state or reflect those of the United States Government or any agency thereof. 


\section{DISCLAIMER}

Portions of this document may be illegible in electronic image products. Images are produced from the best available original document. 


\section{EXECUTIVE SUMMARY}

This report summarizes the Accelerated Reliability testing of five lead-acid batteryequipped Chevrolet S-10 electric vehicles by the U.S. Department of Energy's Field Operations Program and the Program's testing partners, Electric Transportation Applications (ETA) and Southern California Edison (SCE). ETA and SCE operated the S-10s with the goal of placing 25,000 miles on each vehicle within 1 year, providing an accelerated life-cycle analysis. The testing was performed according to established and published test procedures.

ETA obtained their S-10s almost immediately after the dealer received them, while SCE's test vehicles were unused for a long time while in transit from the manufacturer and while at the dealer. The difference in the amount of time that the vehicles went unused, as well as the difference in ambient temperatures between Phoenix and Southern California, resulted in contrasting test results.

In Phoenix, ETA drove the two S-10s a combined total of more than 50,000 miles with only a single battery module failure; each $S-10$ reached end-of-battery life at 25,000 miles. In Southern California, the three S-10s operated by SCE had mechanical or electrical problems that limited their ranges. Most of the problems encountered by the SCE S-10s were due to the time required for transporting the vehicles from the factory and for delivery to the customer. After the battery packs were replaced in all three of SCE's vehicles, the average ranges were 38 to 40 miles. However, testing partners noticed that the ranges would fluctuate from 30 to 45 miles during morning and afternoon driving cycles. The probable cause of these fluctuations was the ambient temperature (the vehicles performed poorly in cooler temperatures).

The S-10s' average ranges were highest during summer months; changes in ambient temperature from night to day and from season-to-season impacted range by as much as 10 miles. Drivers also noted that excessive use of power during acceleration also had a dramatic effect on vehicle range. The spirited performance of the S-10s created a great temptation to inexperienced electric vehicle drivers to "have a good time" and to fully utilize the S-10's acceleration capability. The price of injudicious use of power is greatly reduced range and a long-term reduction in battery life. The range using full-power accelerations followed by rapid deceleration in city driving has been 20 miles or less.

The S-10 Electric has acceleration, handling, and payload capabilities that match or exceed most electric vehicles currently on the market. The vehicle's driving qualities and driver comfort are considered very good. The problems experienced have been largely related to the Delphi $12 \mathrm{~V}$ battery modules originally used. In that regard, GM has been replacing the battery packs of the $\mathrm{S}-10$ s with more reliable and better-performing lead-acid or Nickel Metal Hydride (NiMH) batteries. The Panasonic lead-acid batteries are believed to provide at least $20 \%$ more range and be more reliable. Testing of the S-10s with NiMH batteries suggests that the range will be more than double (95 miles) that of the original Baseline Performance testing results (43.8 miles). 
-

-

-

8

-

-

-

9

.

-

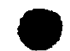

-

-

8
8
8
8
8
8
8 


\section{Contents}

EXECUTIVE SUMMARY .............................................................................................................

1. INTRODUCTION

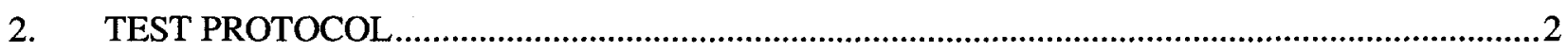

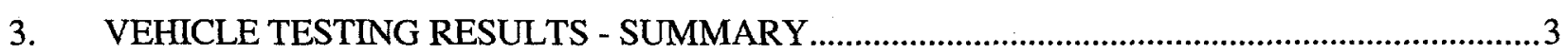

4. ELECTRIC TRANSPORTATION APPLICATIONS - INDIVIDUAL

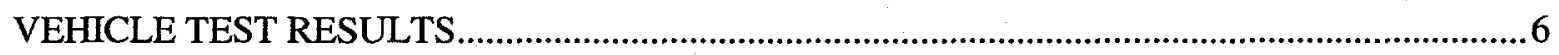

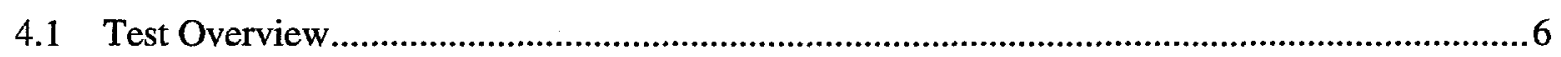

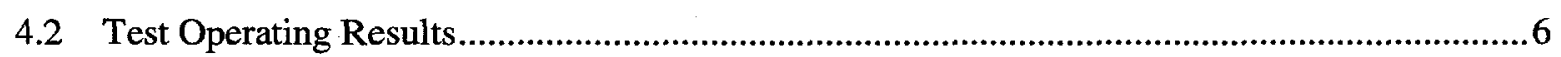

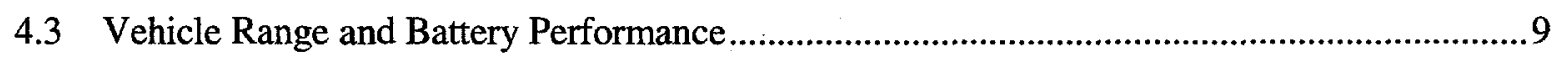

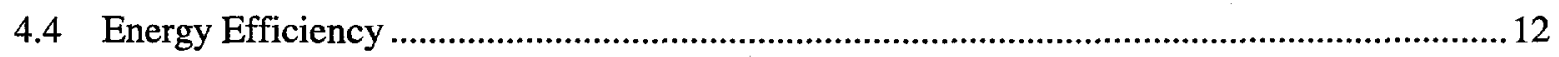

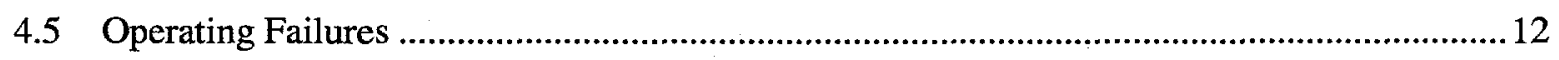

4.6 Maintenance Requirements .............................................................................................. 12

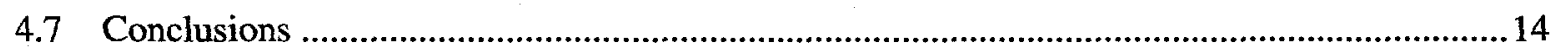

5. SOUTHERN CALIFORNIA EDISON - INDIVIDUAL VEHICLE TESTING RESULTS ............16

5.1 Test Overview.......................................................................................................................

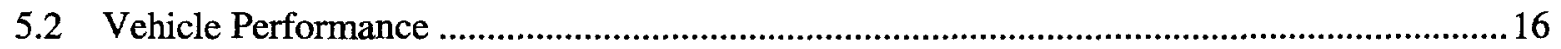

5.3 ABB kWh Meter Energy Data.........................................................................................2.

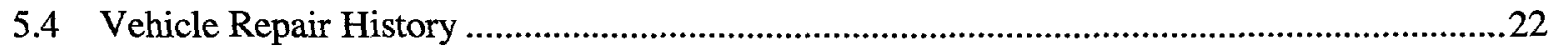

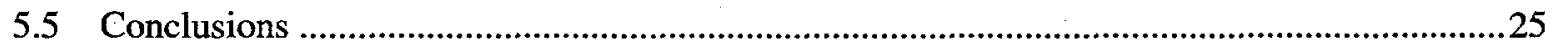

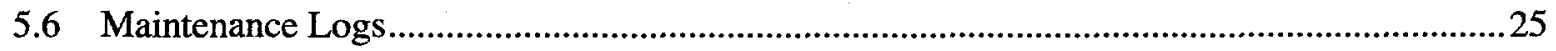

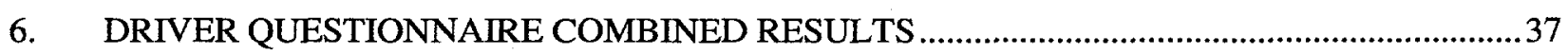

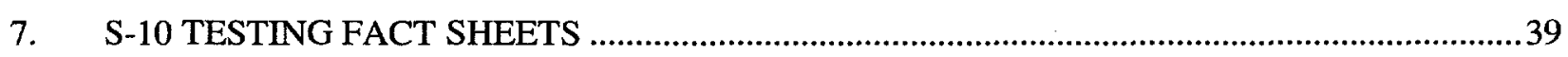




\section{Field Operations Program Chevrolet S-10 (Lead-Acid) Accelerated Reliability Testing - Final Report}

\section{INTRODUCTION}

The Field Operations Program and its predecessor, the Site Operator Program, were established by the U.S. Department of Energy (DOE) to implement electric vehicle activities dictated by the Electric and Hybrid Vehicle Research, Development and Demonstration Act of 1976. In the ensuing years, the Program has evolved in response to new legislation, interests, and technologies. The Program's goals include evaluating electric vehicles in real-world applications and environments, advancing electric vehicle technologies, developing infrastructure elements necessary to support significant electric vehicle use, and increasing the awareness and acceptance of electric vehicles. Personnel of the Idaho National Engineering and Environmental Laboratory (INEEL) manage the Field Operations Program. To support the field evaluation of electric vehicles, during 1996 DOE selected two Qualified Vehicle Testers (QVTs) through competitive bids. One of the QVTs is Southern California Edison Company. The other QVT is a consortium led by Electric Transportation Applications (ETA), with other members consisting of Arizona Public Service (APS), Salt River Project (SRP), and Potomac Electric Power Company (PEPCO). For a more complete description of Program activities, Program reports, and test results, visit the Program's website at http://ev.inel.gov/sop.

One of the field evaluation tasks of the Program is the accelerated reliability testing of commercially available electric vehicles. These vehicles are operated by electric utilities with the goal of placing 25,000 miles per vehicle within 1 year. Since the normal fleet vehicle is only driven approximately 6,000 miles per year, this type of an operations mode allows an accelerated life-cycle analysis of vehicles. Driving is done on public roads in a random manner that simulates actual fleet operations. Data is collected and reported through the INEEL.

This report summarizes the accelerated reliability testing of five lead-acid equipped Chevrolet S-10 electric vehicles by the Field Operations Program and its testing partners. ETA tested two of the S-10s in the greater Phoenix, Arizona area and they were assigned vehicle numbers 497 and 499. SCE's Electric Transportation Division tested the other three S-10s. These three vehicles were assigned to SCE's Electric Vehicle Technical Center (EVTC) located in Pomona, California, and were assigned vehicle numbers 23629, 23630, and 23631. 


\section{TEST PROTOCOL}

During 1997, test procedures were developed to govern the conduct of the Field Operations Program. Specifically, the "Accelerated Reliability Testing Procedures" were issued by SCE in October 1997. The test procedures are available from the Program's Internet web site at http://ev.inel.gov/sop. These procedures define the specific requirements for the operation, maintenance, and ownership of electric vehicles; and provide guidance for the conduct of the accelerated reliability testing of the five Chevrolet S-10s. Input to the test procedures was provided by ETA and by the INEEL. Each vehicle placed into testing was evaluated in accordance with the Accelerated Reliability Testing Procedures. 


\section{VEHICLE TESTING RESULTS - SUMMARY}

The accelerated reliability testing for the Chevrolet $S-10$ s resulted in divergent experiences. While ETA was able to obtain their test vehicles almost immediately after the dealer received them, SCE's test vehicles were not used for a long time while in transit from the manufacturer and while at the dealer. The difference in the amount of time that the vehicles went unused, as well as the difference in ambient temperatures between Phoenix and Southern California, resulted in contrasting test results.

Absent battery issues and the associated range limitations, the S-10s proved to be very desirable vehicles to drive. They exhibited operating characteristics equaling or exceeding (such as acceleration) that of the gasoline-powered S-10. However, the early version of lead-acid batteries used to power the electric S-10s proved to have imperfections when operating conditions were not optimal. In spite of any technical constraints due to the battery technology originally used, the S-10s displayed many positive operating characteristics, which are discussed below.

The two S-10s operated in Phoenix were driven a combined total of more than 50,000 miles with only a single battery module failure. The two vehicles were placed on charge 1,429 and 3,087 times respectively, and they had AC energy efficiencies of 2.25 miles $/ \mathrm{kWh}_{\mathrm{AC}}$ and 2.16 miles $/ \mathrm{kWh}_{\mathrm{AC}}$. Assuming an energy cost of $7 \phi / \mathrm{kWh}$, the energy cost for operating the two vehicles for 50,000 miles, was about $\$ 1,600$; this correlates to about $3.18 \phi / \mathrm{mile}$. The maintenance cost over the test period for these two S-10s was zero. Therefore, the total operating and maintenance costs for the S-10s operated by ETA was $3.18 \notin$ per mile. If battery pack replacement is included in the operating cost at $\$ 5,000$ per pack, the total operating and maintenance cost becomes $23.2 \mathrm{c} / \mathrm{mile}$. Based upon the loss of range and the spread of individual module voltages under load, each of the ETA operated S-10s reached the end of battery life at 25,000 miles.

The lead-acid equipped S-10 is now being offered for lease with 3 year, 36,000 mile warranties that effectively remove the potential battery pack replacement cost. (Previous warranties generally did not cover the full battery replacement cost beyond 1 year). The cost to lease a lead-acid equipped $\mathrm{S}-10$ is about $\$ 350$ per month. Assuming the vehicles are driven about 6,000 miles per year in normal fleet use ( 24 miles per day times 50 weeks) results in a per-milecost of $70 \varnothing$ per mile. Adding the energy cost of $3.18 \varnothing$ per mile results in a life-cycle cost of just over $73 \notin$ per mile.

Most of the S-10s acquired by SCE for fleet-use and accelerated reliability testing have had mechanical or electrical problems, particularly the accelerated reliability test vehicles. It became evident that most of the problems encountered early in the program were due to the time required for transporting the vehicles from the factory and for delivery to the customer. There was no record of what the state-of-charge (SOC) of the battery was when the vehicles left the factory. Unfortunately, after the vehicles were received at the dealer, they were stored off-charge for several months while the paperwork was being completed. It should be recognized that the accelerated reliability testing process is a test of commercially available vehicles; and, part of the commercially available process includes shipment through the vehicle dealer system and all of 
the benefits or negatives that entails. SCE's experience highlights the different shipping and handling requirements of electric vehicles compared to internal combustion-powered vehicles.

After the battery packs were replaced in all three of SCE's vehicles, average ranges were between 38 and 40 miles. However, testers noticed that the ranges would fluctuate from 30 to 45 miles during morning and afternoon driving cycles. The probable cause of these fluctuations was the ambient temperature (the vehicles performed poorly in cooler temperatures).

ETA also reported variations in vehicle range, with their S-10s having the highest average ranges during the summer months. Changes in ambient temperature from night to day and from season to season impacted range by as much as 10 miles (25\%). However, this can be mitigated by garaging the vehicles overnight and during the day when not in use.

The S-10 drivers also noted that excessive use of power during acceleration had a dramatic effect on vehicle range. The traction drive of the $S-10$ provides very spirited performance and creates a great temptation to the inexperienced electric vehicle driver to "have a good time" and to fully utilize the performance the vehicle offers. Unfortunately, the price of injudicious use of power is greatly reduced range and a long-term reduction in battery life. The range using full-power accelerations followed by rapid deceleration in city driving has been 20 miles or less.

Charge times also varied significantly due to environmental factors. The S-10 battery pack is actively cooled by the vehicles air conditioning system. Refrigerant is diverted to a battery pack evaporator/fan when battery pack temperatures exceed $45^{\circ} \mathrm{C}$. The high ambient temperatures in Phoenix presented a significant challenge to the pack cooling system. During summer daylight hours, air conditioning resources were always diverted to pack cooling, leaving the cabin without air conditioning. It was only well after dark that the pack would ever cool enough for pack cooling to stop and the refrigerant was diverted back to the cabin. This was the source of many negative driver comments with regard to cabin comfort. The high battery pack temperatures also frequently extended charge times, as the chargers significantly reduced charging power at high battery temperatures

The range of the S-10, as originally equipped with the Delphi lead-acid batteries, presented a challenge in finding applications where the mission requirements are enveloped by the vehicle range. Typically, fleet missions requiring a range of 25 miles or less are appropriate. The mission should also require daily use to ensure repeatable performance. Driver training should be provided to inform the driver of the effect of high power use on both range and battery life, as well as to instruct the driver in energy-saving driving techniques.

The S-10 electric has acceleration, handling, and payload capabilities that match or exceed most electric vehicles currently on the market. The vehicle's driving qualities and driver comfort are considered very good. The problems have been largely related to the Delphi $12 \mathrm{~V}$ battery modules. In that regard, GM has been diligently making an effort to replace the battery packs of the S-10s with more reliable and better performing lead-acid or nickel/metal-hydride batteries. Future lead-acid battery equipped S-10s will have Panasonic modules and it is believed that these will give at least $20 \%$ more range and be more reliable. Initial testing of the S-10s with Nickel Metal Hydride batteries suggests that the range will be more than double ( 94 miles) that 
of the original Baseline Performance testing results (43.8 miles for drive cycle tests of the original S-10s equipped with Delphi lead-acid batteries).

The individual vehicle test results for the five S-10s are presented in the following sections, grouped by the QVT that performed the tests. 


\section{ELECTRIC TRANSPORTATION APPLICATIONS - INDIVIDUAL VEHICLE TEST RESULTS}

\subsection{Test Overview}

ETA's Chevrolet S-10s were delivered to the local Chevrolet dealer in Phoenix during September 1997. ETA inspected the vehicles took delivery within 2 days. They assigned the vehicles numbers 497 and 499 and placed them into take-home duty with range requirements of 25 to 35 miles. To begin testing, they installed chargers with kilowatt-hour (kWh) meters at the homes of the drivers taking the vehicles overnight. Additionally, dedicated chargers were installed at ETA's office to allow charging the vehicles during the day and operating them for an additional charge-cycle. A dedicated driver was assigned to conduct the daytime drive-cycle, operating the vehicles 5 days per week. This allowed two full drive-cycles to be accomplished 5 days per week and incidental mileage to be accumulated by the take-home drivers over nights and weekends. Monthly, ETA collected mileage and $\mathrm{kWh}$-usage data along with maintenance records and operating failure data.

\subsection{Test Operating Results}

The vehicles, as shown in Figure 1, were equipped with 26, 12-volt, 48-Ah (C/2) Delphi modules in a single string. The vehicles were charged exclusively using Delco inductive chargers with an output of $6.6 \mathrm{~kW}$ (OEM charger). The vehicles were operated daily to average 500 miles per week. Vehicles 497 and 499 were placed in service in September 1997, and respectively accumulated 25,060 miles and 25,077 miles of service through November 17, 1998 (the date of the final range test). Figures 2 and 3 present monthly mileage accumulated on each vehicle. 




Figure 1. Chevrolet S-10 accelerated reliability test Vehicles 497 and 499 being charged at the Electric Transportation Applications facility. 


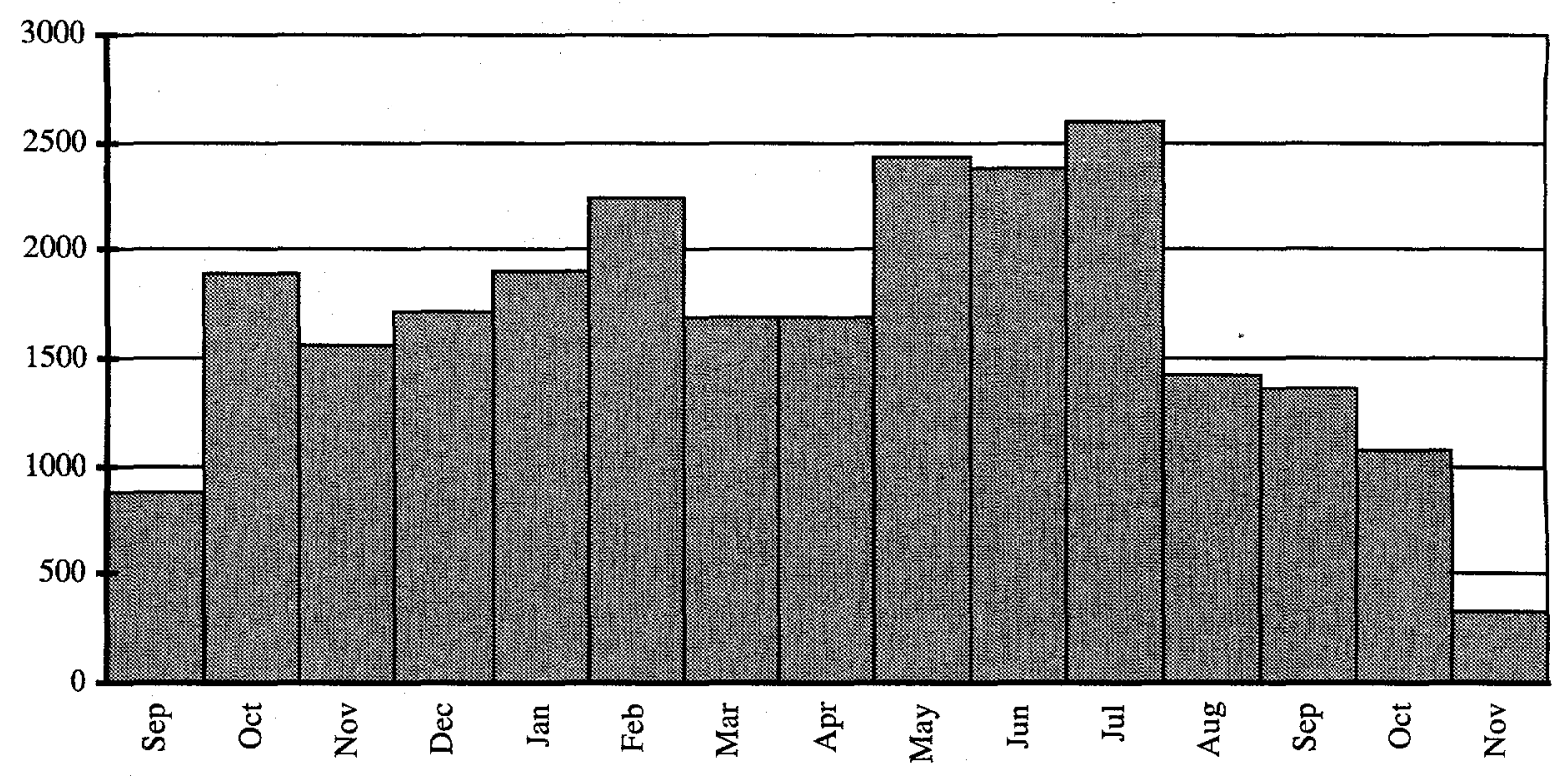

Test Month (97/98)

Figure 2. Miles driven per month by ETA Vehicle 497.

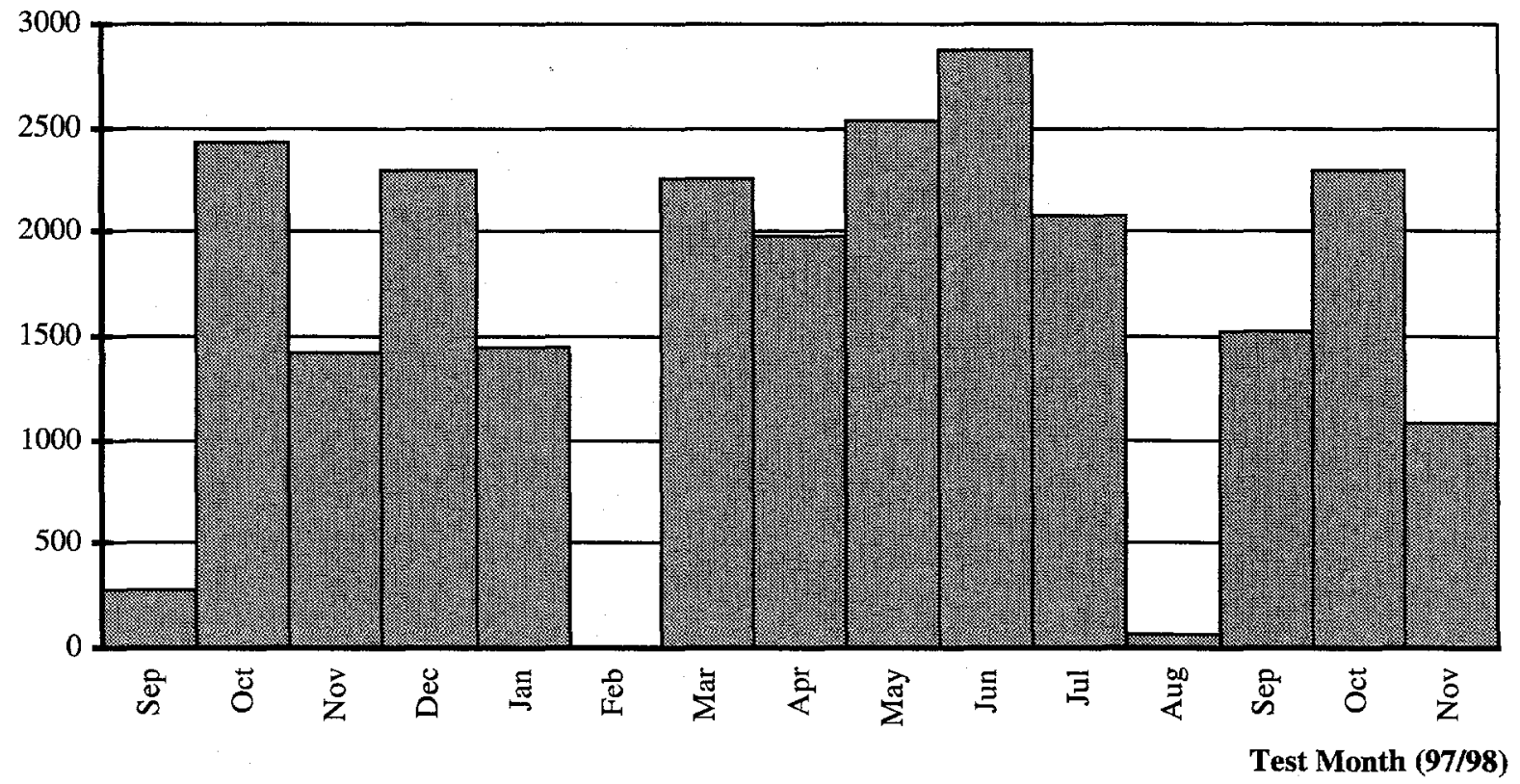

Figure 3. Miles driven per month by ETA Vehicle 499. During February 1998, Vehicle 499 was out of service due to a collision. During August and September 1998, Vehicle 499 underwent warranty work and a module replacement. 


\subsection{Vehicle Range and Battery Performance}

Vehicle range (implicitly battery capacity) was tracked using an average of the distance achieved during the daily full discharge drive cycle and by conducting constant speed range tests on a closed track per the EV America testing protocol (available from http:/lev.inel.gov/sop). Figures 4 and 5 present operating characteristics of the daily full discharge drive-cycle. Drivers of the S-10 vehicles were experienced electric vehicle drivers and typically obtained 40 miles range or greater.

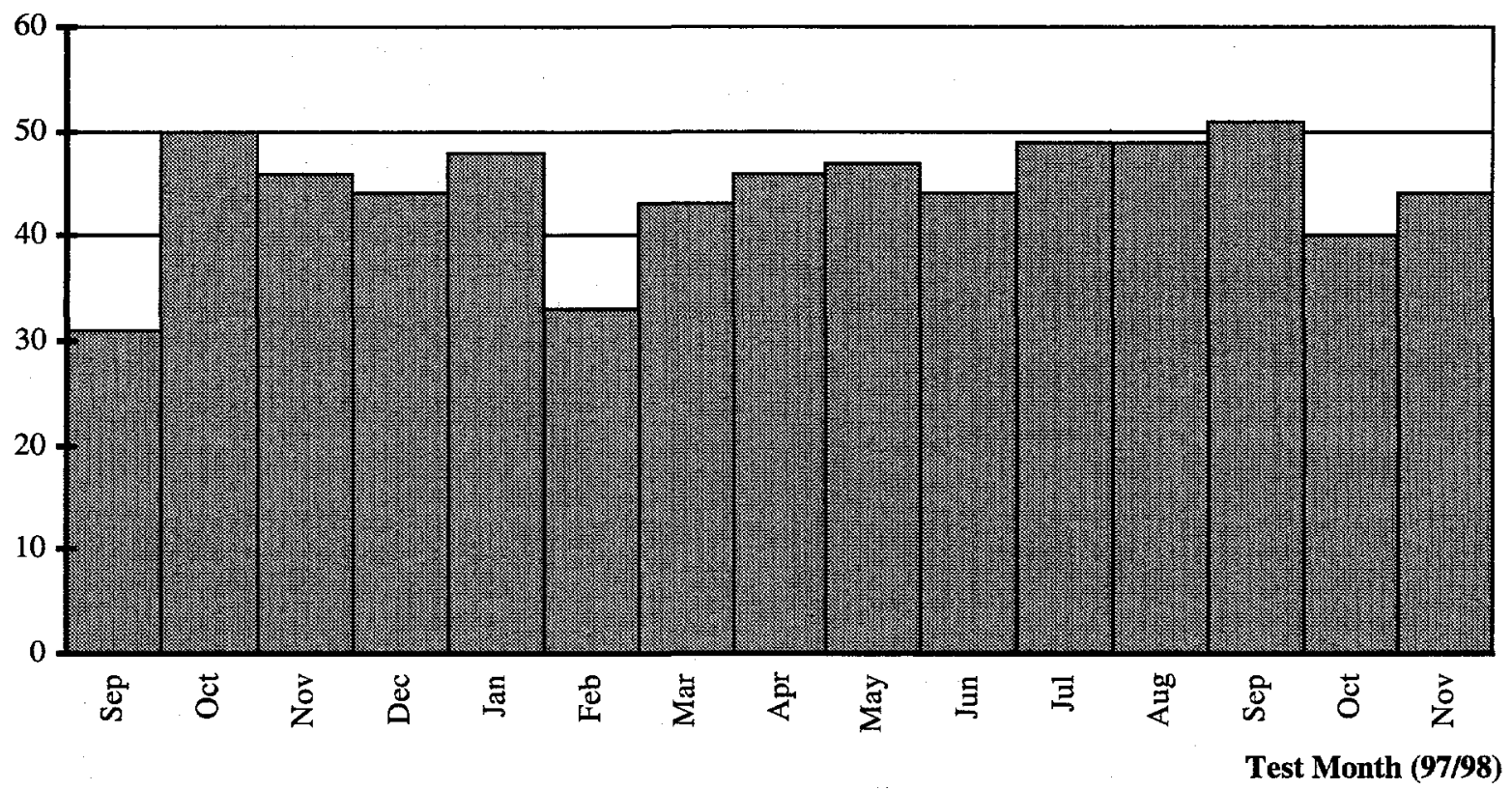

Figure 4. Usable vehicle driving range (miles) by month for ETA Vehicle 497. 


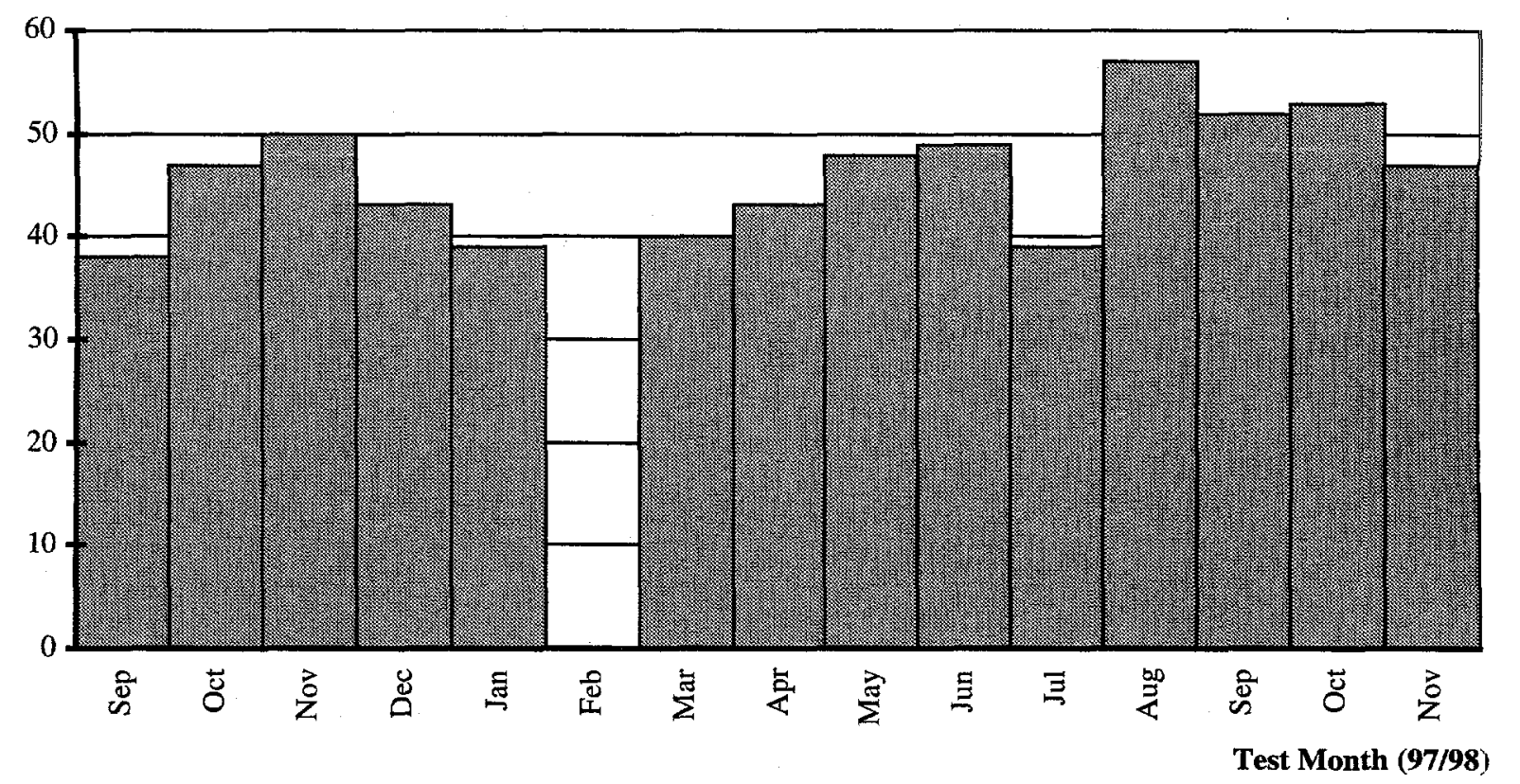

Figure 5. Useable vehicle driving range (miles) by month for ETA Vehicle 499. Vehicle 499 was not driven during February due to a collision.

Table 1 presents the results of the constant speed range tests. Shortly after the November range test, both Vehicle 497 and Vehicle 499 suffered significant range loss. It appears that the reduction in range of Vehicle 497 to 44.8 miles in the November 17, 1998 range test was a precursor to battery pack failure. With the reduction in range in both vehicles, battery pack load tests under acceleration were conducted. These results are presented in Figures 6 and 7 for Vehicles 497 and 499 respectively. Based upon the significant loss of range (Table 1) and upon the significant spread of individual module voltages under load (Figures 6 and 7), the battery packs in Vehicles 497 and 499 were considered to have reached end of life. The graphed decreases and subsequent rebounds in voltages (Figures 6 and 7) result from reductions in load (acceleration) during the testing.

Table 1. Vehicles 497 and 499 range test results. The vehicles were tested using cruise control (45 mph) on a closed track. Note: The baseline performance (EV America) test result for the Chevrolet S-10 constant speed $45 \mathrm{mph}$ range test is 60.4 miles.

\begin{tabular}{cccccc}
\hline Test Date & \multicolumn{2}{c|}{ Vehicle 497 } & \multicolumn{2}{c}{ Vehicle 499 } \\
\hline & $\underline{\text { Range }}$ & $\underline{\text { Odometer }}$ & $\underline{\text { Range }}$ & $\underline{\text { Odometer }}$ \\
$10 / 7 / 97$ & 67.5 & 2,258 & 57.9 & 1,794 \\
$4 / 28 / 98$ & 60.8 & 14,285 & 58.0 & 12,517 \\
$11 / 17 / 98$ & 44.8 & 26,494 & 58.8 & 25,606 \\
\hline
\end{tabular}




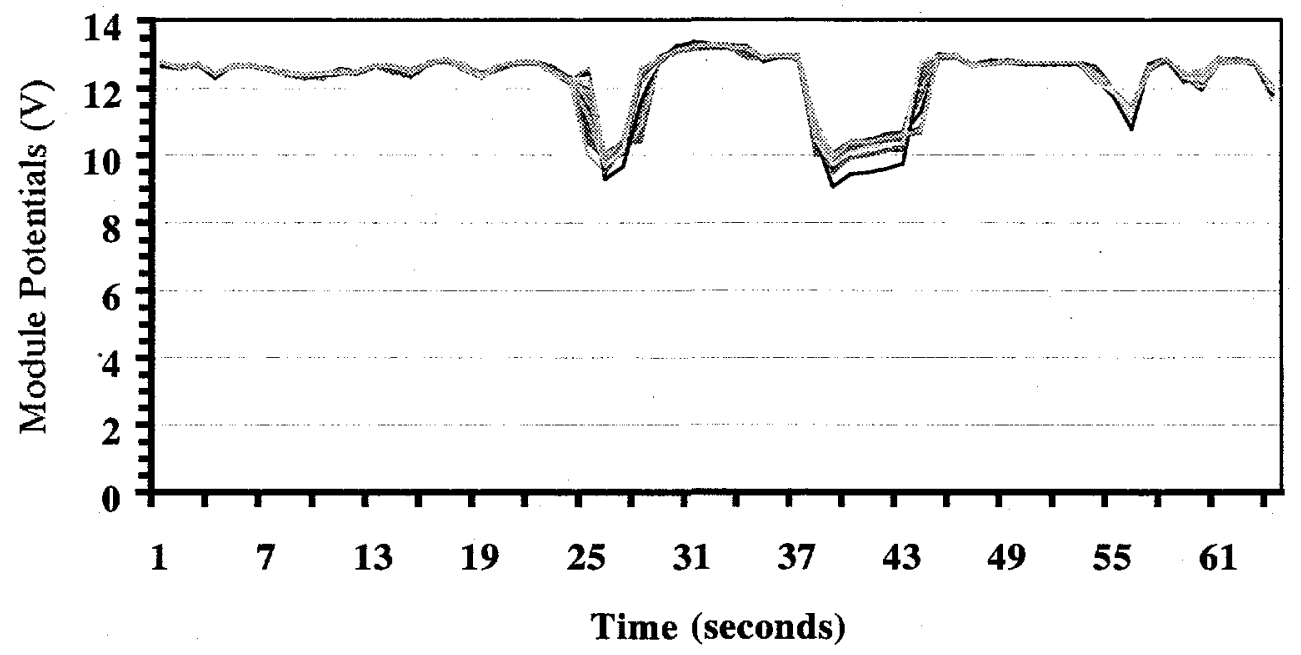

Figure 6. Test results for ETA Vehicle 497 battery module voltages under load.

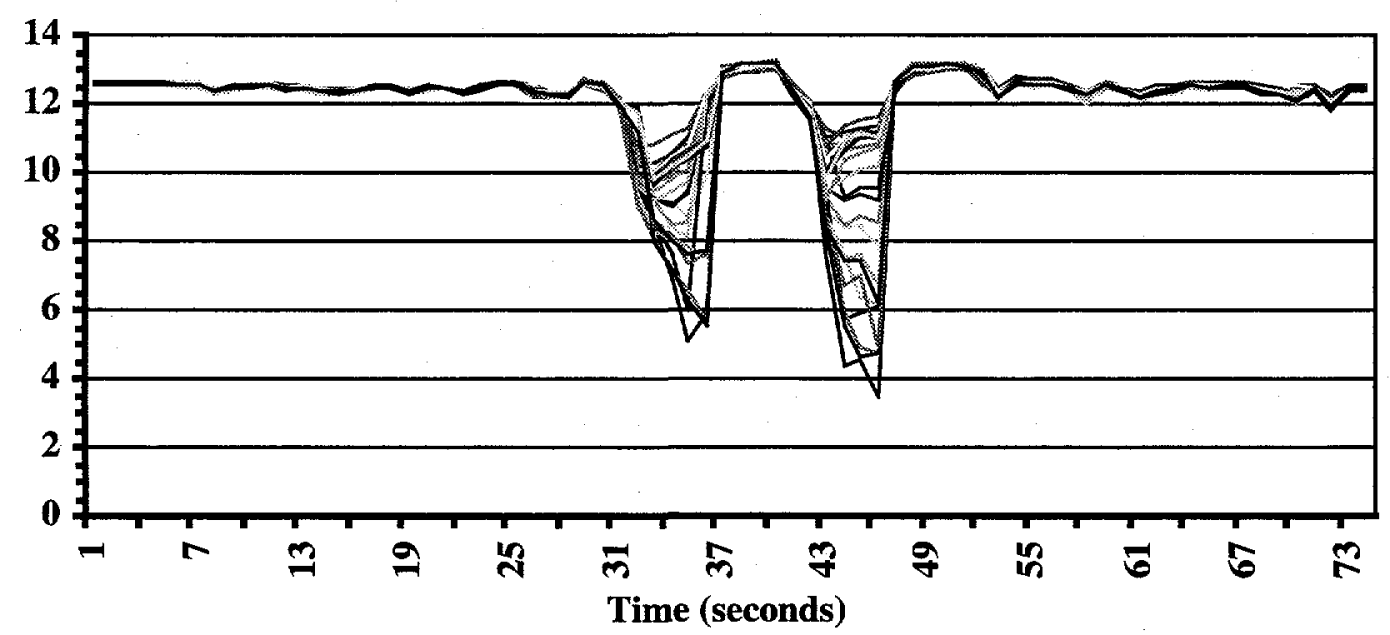

Figure 7. Test results for ETA Vehicle 499 battery module voltages under load.

Kilowatt-hour usage and charge initiation times were available from the charge meters installed on the off-board pedestal chargers. Based on this data, Vehicles 497 and 499 were placed on charge 1,439 and 3,087 times respectively. Many of these charges were partial charges reflecting a tendency to charge the vehicles at every opportunity to assure sufficient charge to meet mission requirements. Average trip length between charge events was 17.4 miles and 8.1 miles for Vehicles 497 and 499 respectively. The average energy returned per charge for 
Vehicles 497 and 499 was $7.73 \mathrm{kWh}$ and $3.77 \mathrm{kWh}$ respectively. This represents $52 \%$ and $25 \%$ of available energy, assuming a $15 \mathrm{kWh}$ battery pack (48 Ah at 312 volts).

Assuming an energy efficiency of $2.76 \mathrm{miles} / \mathrm{kWh}$ (DC energy based on EV America testing), the total energy delivered by the battery packs in Vehicles 497 and 499 was $9,080 \mathrm{kWh}$ and $9,086 \mathrm{kWh}$ respectively through November 17, 1998. Assuming a nominal pack potential of 312 volts, the battery packs delivered 29,102 Ah and 29,121 Ah respectively. This represents approximately 600 times the $\mathrm{C} / 2$ rate.

\subsection{Energy Efficiency}

Vehicles 497 and 499 operated at an AC energy efficiency of 2.25 miles/kWh $\mathrm{kC}$ and 2.16 miles/ $\mathrm{kWh}$ AC respectively. While the efficiency was negatively impacted by the pervasive use of opportunity charging, it compares favorably with the $2.13 \mathrm{miles} / \mathrm{kWh} \mathrm{AC}_{\mathrm{AC}}$ recorded during the Program's Baseline Performance (EV America) testing. (The Baseline Performance and the Southern California Edison Pomona Loop Fact Sheets for the lead acid S-10 are provided at the end of this report. See the Program's Internet site http://ev.inel.gov/sop for Baseline Performance and Pomona Loop Fact Sheets for other models of vehicles).

At $7 \phi / \mathrm{kWh}$ AC the energy cost for operating the $\mathrm{S}-10$ electric pickup truck is $3.1 \% / \mathrm{mile}$ and $3.2 \phi /$ mile for Vehicles 497 and 499 respectively. The energy cost for operating the entire 25,000 mile test (assuming $7 \notin / \mathrm{kWh}$ ) was $\$ 778.18$ and $\$ 814.43$ for Vehicles 497 and 499 respectively.

\subsection{Operating Failures}

No on-the-road failures occurred with either Vehicle 497 or 499 during the duration of the test. Early in the test, both vehicles would occasionally display a "wait" indicator upon restart after a brief period of driving. This problem was resolved with the software updates installed on each vehicle as part of the Chevrolet update campaign.

A high failure rate for the off-board Delco charger was experienced. The charger power electronics for each vehicle failed once during the test and required replacement. Charger cords often would not retract into the pedestal mounted charge units used for the test. While this did not impact operability, it was a nuisance to the vehicle operators. Delco has since updated the version of the Delco charger used with the S-10s.

\subsection{Maintenance Requirements}

Minimal corrective maintenance and no preventative maintenance has been performed to support the operation of S-10 Vehicles 497 and 499 . The greatest time out of service was to replace one battery module on Vehicle 499 . This evolution should have taken only 1-2 days but required 37 days as the Phoenix dealer is not qualified to perform battery maintenance. The module was replaced by General Motors personnel at their Arizona Proving Ground facility.

At no time during the test did a vehicle strand a driver on the road. Table 2 presents the maintenance required and the days out of service for each maintenance activity. 
The reservoir for Inverter cooling fluid was a source of problems until it was replaced with an updated design. Vehicle 499 was taken to the dealer with a leaking reservoir and low fluid level on $11 / 18 / 98$. The dealer indicated that they did not have replacement fluid and would have to order such. After 3 days the vehicle was returned to service while awaiting arrival of replacement fluid. After 5 weeks of waiting for fluid, ETA purchased fluid from a local Saturn dealer and topped off the reservoirs of both Vehicle 499 and Vehicle 497 . The reservoirs on both vehicles continued to leak and required that the fluid be topped off periodically. Reservoirs were ultimately replaced as part of the Customer Satisfaction Improvement Program. It is not expected that the reservoirs will be a problem for future operations.

Total mileage on Vehicle 499 was reduced by its involvement in a traffic accident. The vehicle was hit from the rear by a pickup truck on Interstate 17 and forced into the rear of a large delivery van. Vehicle 499 suffered damage to both the front and rear of the vehicle; no damage was sustained by the drive system, batteries, or charge port. Repair of the vehicle was performed promptly by the local Chevrolet dealer once approval from the insurance company was received. No long-term affects of the damage or repair have been apparent in the subsequent operation of Vehicle 499.

The industry has presumed that tire wear would be an issue with electric vehicles due to the vehicles' increased weight. Tire wear, however, has not been an issue with the S-10 vehicles operated by ETA. The vehicles are equipped with Uniroyal Tiger Paw P205/75 R15 tires. As of the end of the test, tread remaining on the front tires was 7/32 in. and on the rear tires 10/32 in. When new, the tires had 13/32 in. tread depth with $11 / 32 \mathrm{in}$. of useable tread. This indicates that the front tires are approximately $55 \%$ worn, and projects a total tread life of between 45,000 and 50,000 miles for the front tires. The rear tires should have a longer total tread life. This is comparable to standard S-10 performance in Phoenix.

Table 2. Electric Transportation Applications Vehicles 497 and 499 maintenance requirements.

\begin{tabular}{llc}
\hline Service Dates & Service Required & Days out of service \\
\hline Vehicle 497 & & \\
\hline $1 / 26 / 98$ & Replace front axles in response to recall campaign & 1 \\
$10 / 27-10 / 30 / 98$ & Customer Satisfaction Improvement Program items & 4 \\
Vehicle 499 & & 2 \\
$10 / 1-10 / 2 / 97$ & Adjust driver side window & 3 \\
$11 / 18-11 / 21 / 97$ & Low Inverter cooling fluid level & 1 \\
$1 / 28-3 / 10 / 98$ & Replace front axles in response to recall campaign & 39 \\
& Repair collision damage & 4 \\
$8 / 4-9 / 15 / 98$ & Customer Satisfaction Improvement Program items & 37 \\
\hline
\end{tabular}




\subsection{Conclusions}

The S-10 vehicles tested by ETA have provided over 50,000 miles of service with minimal maintenance requirements and no breakdowns. With a reliable driving range of 40 miles in moderate ambient temperatures, proper mission selection and driver training for the S-10 is critical. However, in the appropriate mission, the S-10 has the potential to provide excellent performance and reliability. The $\mathrm{S}-10$ batteries have been capable of providing range equal to that achieved in the Program's Baseline Performance (EV America) testing throughout the test period. The use of trained and conservative drivers is a key factor in the successful application of the S-10 and should be an integral part of the mission selection and operator training process. be drawn:

Based on the Accelerated Driving Test of the S-10 Electric, the following conclusions can

- The S-10 Electric provides more than adequate performance and handling for lightduty applications.

- The two S-10s operated very economically over the test period. Their energy efficiency over the test period averaged an admirable $2.20 \mathrm{miles} / \mathrm{kWh}$ AC. This correlates to $3.18 \phi / \mathrm{mile}$ at an energy cost of $7 \notin / \mathrm{kWh}$. The maintenance cost over the test period was zero. Therefore, the total operating and maintenance cost for the S-10 Electric over the test period was $3.18 \notin /$ mile. If battery pack replacement is included in the operating cost at $\$ 5,000$ per pack, the total operating and maintenance cost becomes $23.2 \phi / \mathrm{mile}$.

- Based on driver comments, drivers were very happy with the vehicle performance. Restricted range was a concern to drivers and required them to carefully plan any trips that were not routinely conducted. Chargers were easy to operate and drivers appreciated the percent state-of-charge and time-remaining displays to assist in charge planning.

- The range of the $\mathrm{S}-10$ presents a challenge in finding applications where the mission requirements are enveloped by the vehicle range season-to-season. Typically, fleet missions requiring a range of 25 miles or less are appropriate. The mission should also require daily use to ensure repeatable performance. Driver training should be provided to inform the vehicle driver of the effect of high power use on both range and battery life, as well as to instruct the driver in energy saving driving techniques.

- $\quad$ Range of the S-10s varied due to environmental factors and driving protocol. Ambient temperature was observed to have a significant effect on vehicle range. Changes in ambient temperature from night to day and from season to season impacted range by as much as 10 miles (25\%). This can be mitigated by garaging the vehicles overnight and during the day when not in use. The S-10 drivers also noted that excessive use of power on acceleration had a dramatic effect on vehicle range. The traction drive of the S-10 provides very spirited performance and creates a great temptation to the inexperienced electric vehicle driver to "have a good time" and fully utilize the performance the drive offers. Unfortunately, the price of injudicious 
use of power is greatly reduced range and a long-term reduction in battery life. The range using full power accelerations followed by rapid deceleration in city driving has been 20 miles or less.

- Charge times also varied significantly due to environmental factors. The S-10 Electric battery pack is actively cooled by the vehicle's air conditioning system. Refrigerant is diverted to a battery pack evaporator/fan when battery pack temperatures exceed $45^{\circ} \mathrm{C}$. The high ambient temperatures in Phoenix presented a significant challenge to the pack cooling system. During summer daylight hours, air conditioning resources were always diverted to pack cooling, leaving the cabin without air conditioning. It was only well after dark that the pack would ever cool enough for pack cooling to stop and divert refrigerant back to the cabin. This was the source of many negative driver comments with regard to cabin comfort. The high battery pack temperatures also frequently extended charge times as the chargers significantly reduced charging power at high battery temperatures. On a positive note, the high battery temperatures contributed to increased range (for the $S-10$ ) during warm Phoenix days as can be seen from Figures 4 and 5 . 


\section{SOUTHERN CALIFORNIA EDISON - INDIVIDUAL VEHICLE TESTING RESULTS}

\subsection{Test Overview}

Three Chevrolet S-10s were placed into accelerated reliability testing at SCE starting in August 1997, and assigned numbers 23629, 23630, and 23631. After initial conditioning, full vehicle performance characterization was performed on vehicle 23630 . This included range, (Pomona Urban and Freeway Loops - with minimum and maximum payloads, with and without accessories), acceleration, braking, and charger tests. The other vehicles were cycled until being placed with users.

Before the vehicle testing commenced, employees with a commuting distance sufficiently long (but within the maximum range of the vehicle) were selected to be users of the vehicles. Soon after the vehicles were put in service, it became apparent that because of the limitations of the vehicles in terms of range and functional reliability, the three S-10s would have to be assigned to different users with shorter range requirements (15 to 20 miles round-trip commuting distance). Throughout the rest of the test period, most of the S-10s were shifted between different users or assigned to the EVTC (Figure 8) to be cycled and used for daily operations.

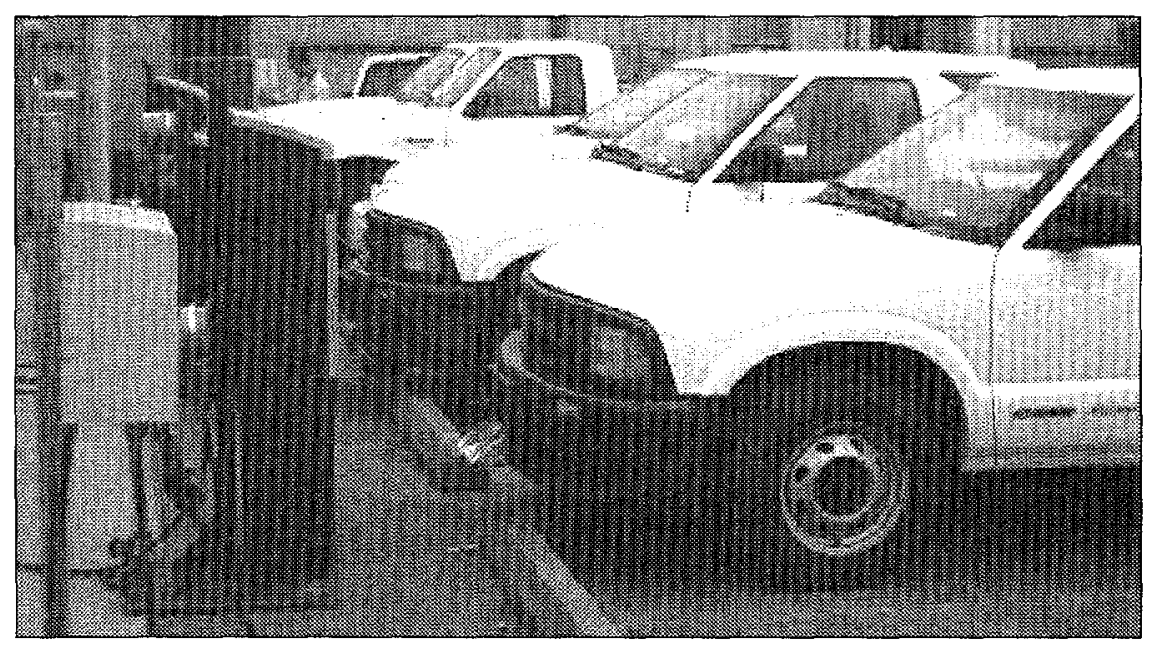

Figure 8. S-10 vehicles being charged at Southern California Edison's Electric Vehicle Technical Center.

\subsection{Vehicle Performance}

The first three S-10 electric vehicles delivered to SCE, during August 1997, were designated DOE Reliability test vehicles. Their initial range tests on the Urban Pomona Loop (an urban loop of about 20 miles) yielded 35,43 , and 39 miles, respectively.

After approximately November 1997, the vehicles were reassigned and periodically range tested in an effort to observe changes in range and battery capacity. The range testing results are 
shown in Figures 9, 10 and 11. The vehicle reassignments did not result in any range improvements, but it did reveal the fact that the range was highly dependent on ambient temperature, with a difference of as much as 10 miles between morning and afternoon drives. The vehicles were assigned to users with one-way commuting distances of 6 to 19 miles. When repairs were needed, they were made at the EVTC, and then a range test was conducted.

Figure 12 shows the monthly mileage for the three vehicles, and documents that SCE was not able to get consistent mileage from the vehicles due to breakdowns and required repairs. Figure 13 shows the progression of odometer readings of the vehicles. The periodic decreases in slope of the graphs are, again, representative of vehicle breakdowns and the resulting time-outof-service for repairs.

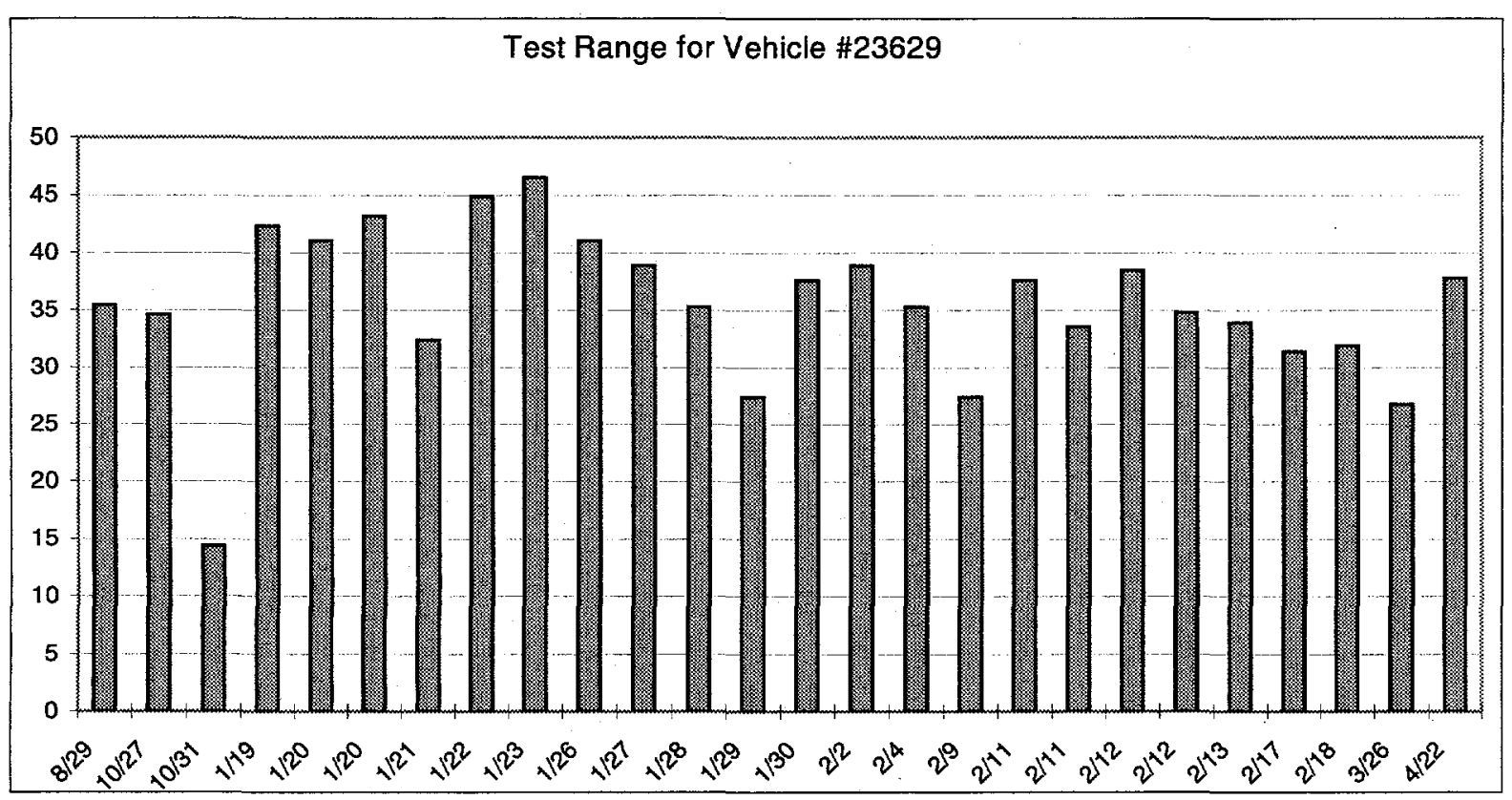

Figure 9. SCE vehicle 23629 Urban Pomona Loop Test Range. The left axis is miles (0 to 50). 


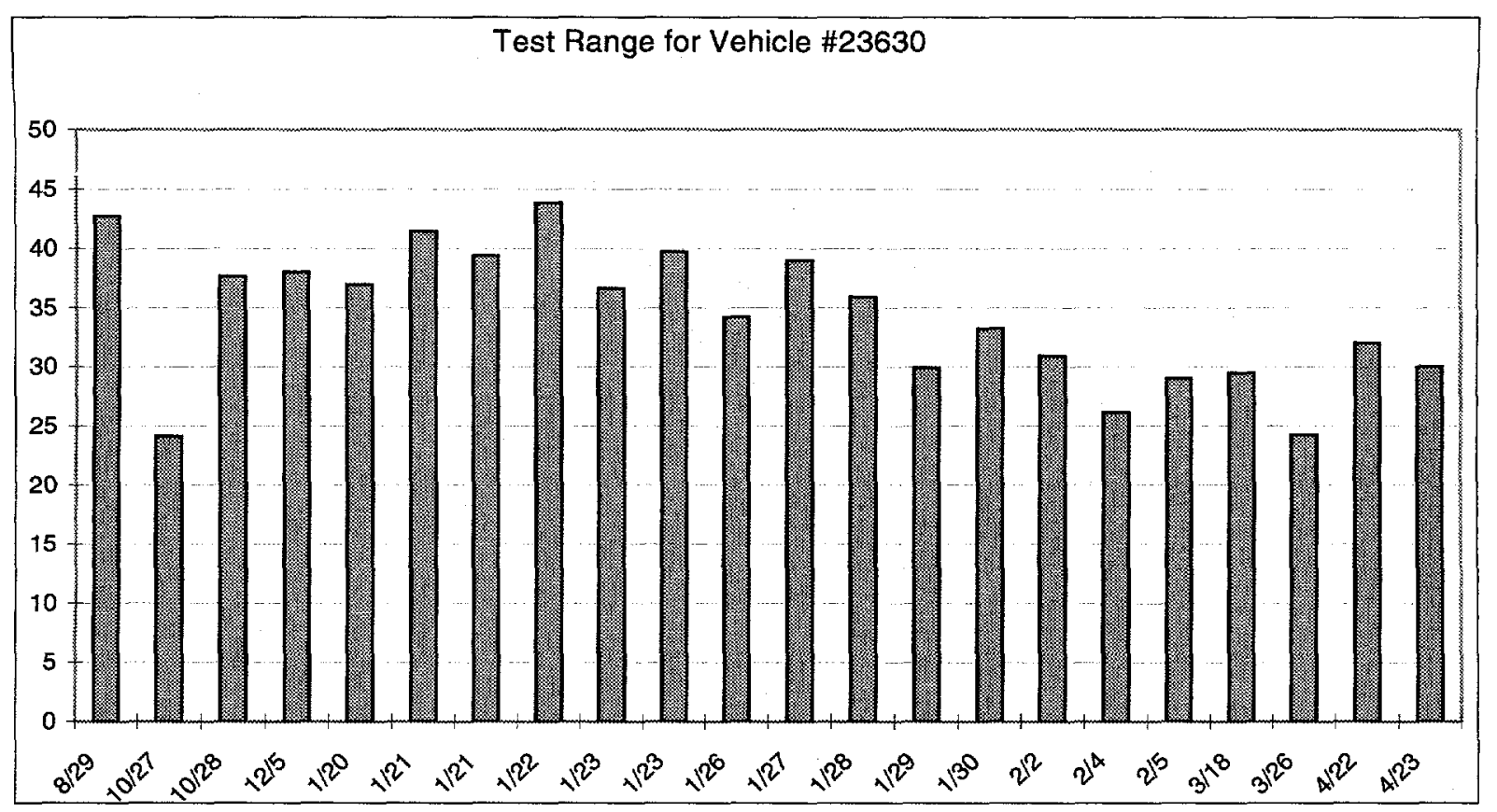

Figure 10. SCE Vehicle 23630 Urban Pomona Loop Test Range. The left axis is miles ( 0 to 50).

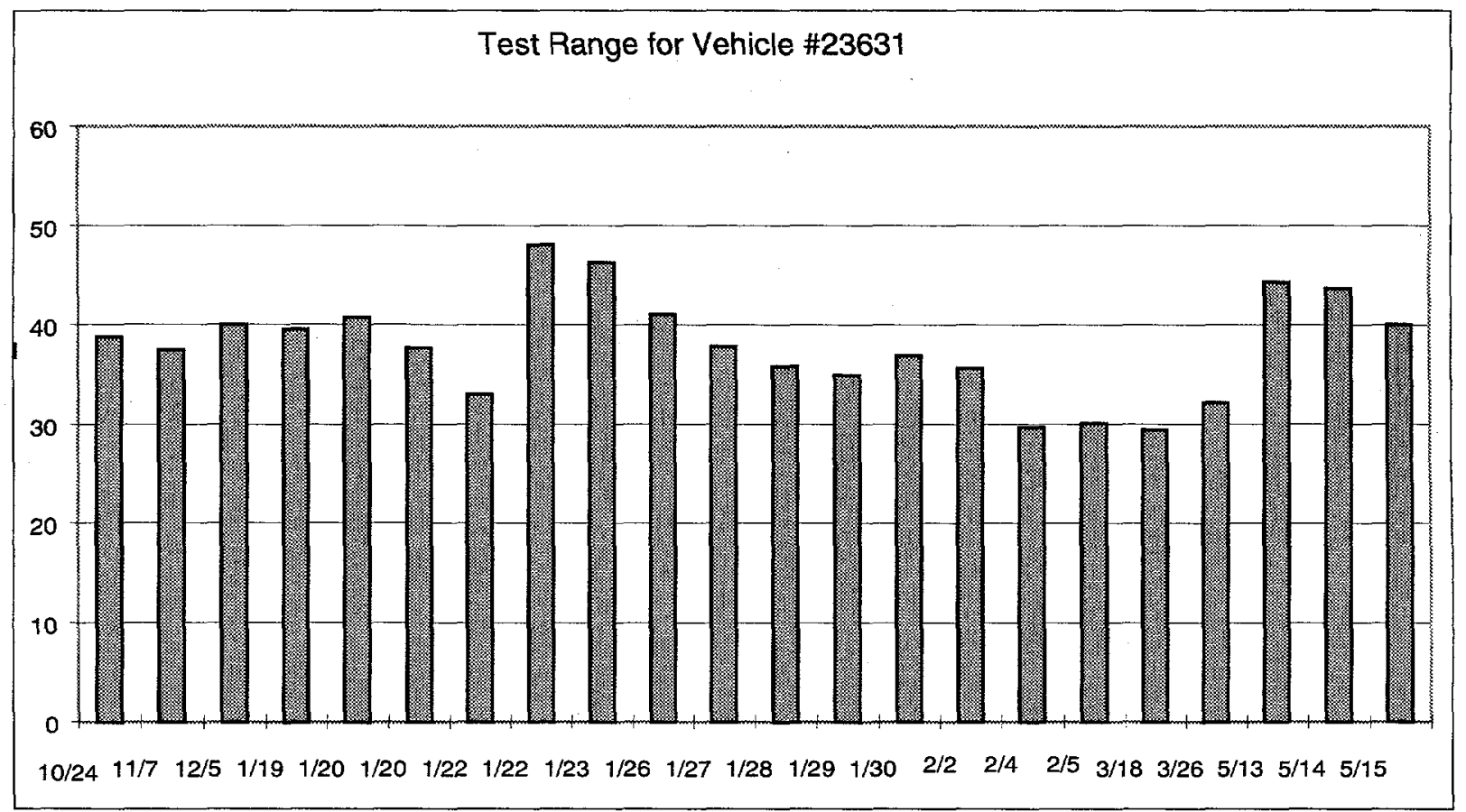

Figure 11. SCE vehicle 23631 Urban Pomona Loop Test Range. The left axis is miles ( 0 to 60). 


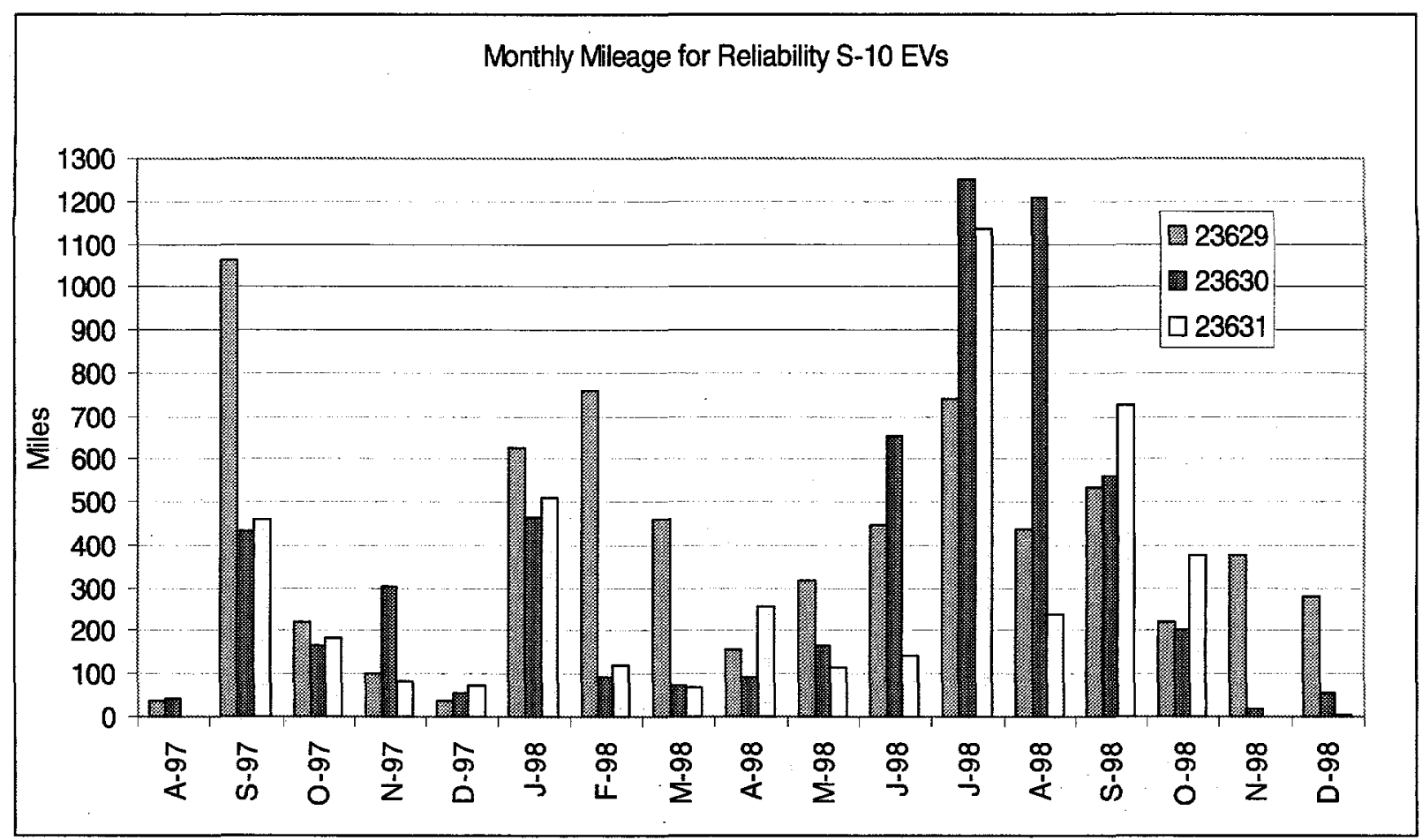

Figure 12. Monthly mileage for SCE's S-10 electric vehicle reliability vehicles.

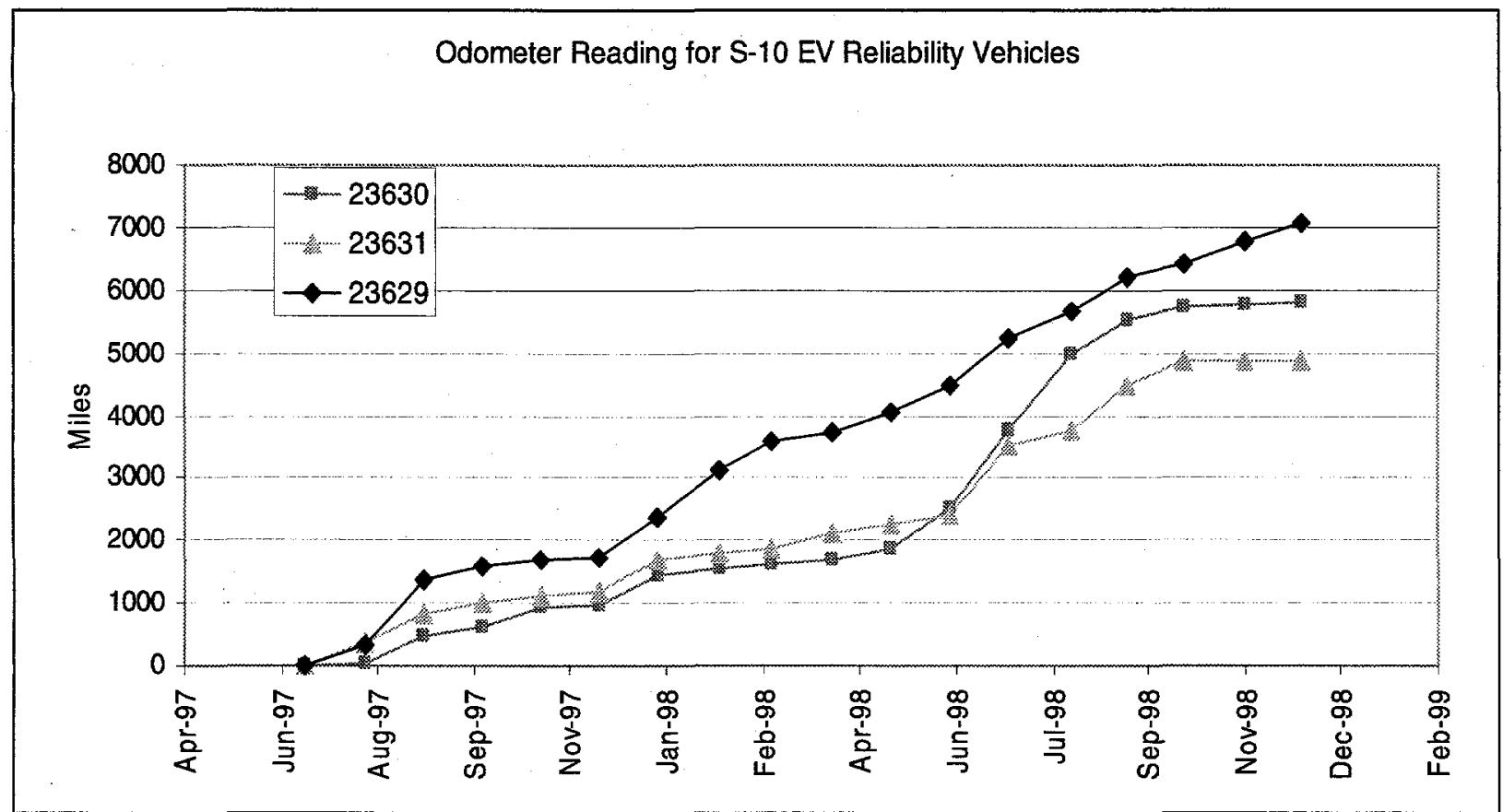

Figure 13. Odometer reading for Reliability Vehicles. 


\subsection{ABB kWh Meter Energy Data}

The ABB meter (Figure 14) data for 1998 is shown in Table 3. For the fourth quarter, energy data was not collected for vehicle 23629 - the only one kept in service. The other two vehicles were kept at the EVTC after being returned due to low range. They were tested on the road and in the shop, where the battery pack was discharged with a load bank and then recharged. Therefore, the data in Table 3 for 23630 and 23631 shows energy usage with little or no mileage on the vehicles for those months.

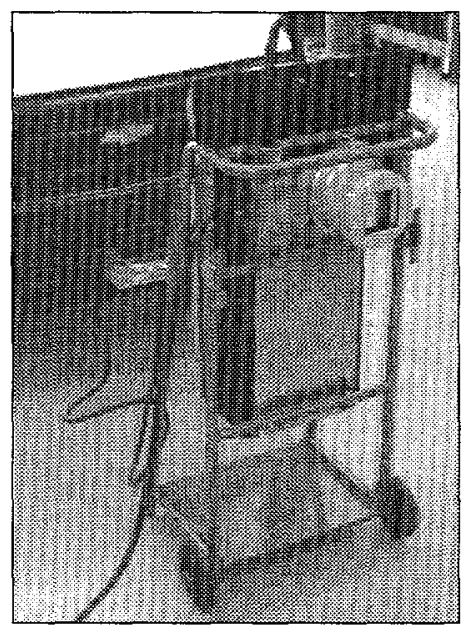

Figure 14. S-10 charger mounted on cart with $\mathrm{ABB} \mathrm{kWh}$ meter.

The calculated data (such as time on charge, miles per charging event, miles per $\mathrm{AC} \mathrm{kWh}$, and $\mathrm{AC} \mathrm{kWh}$ ) in Table 3 is dependent on how the vehicle is used. For the vehicles that were in repair, they were not being driven and charged normally, which distorts the data. In those cases, that calculation was omitted.

The average energy used per-mile-of-driving for all three vehicles was $0.58 \mathrm{AC} \mathrm{kWh}$, or 1.72 miles per $\mathrm{kWh}$. This value is much higher than the average value $(0.476 \mathrm{AC} \mathrm{kWh}$, or 2.1 miles per $\mathrm{kWh}$ ) obtained during SCE's vehicle performance characterization (November 1997) under all conditions (minimum/maximum payload, with/without auxiliary loads). The average miles driven by the users per charging event was 17.4 miles. This value is less than $50 \%$ of the average range of 38 miles in the characterization. So the vehicles were operated conservatively and well below the potential maximum range in light of their history of unexpected problems with driving range. The average time on charge was 2.6 hours. The total time on charge for a charge from $0 \%$ state-of-charge was 3.7 hours in the characterization. The average monthly mileage was 394 miles. 
Table 3. ABB Meter energy data for Southern California Edison's S-10 Electric Vehicles during 1998.

\begin{tabular}{|c|c|c|c|c|c|c|c|c|c|c|}
\hline 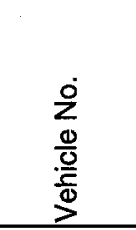 & 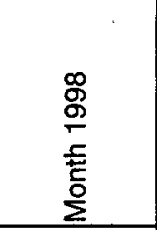 & 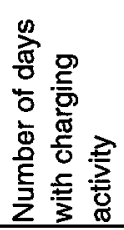 & 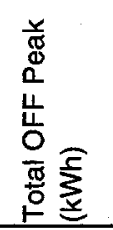 & 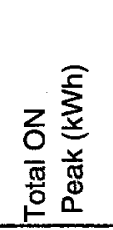 & 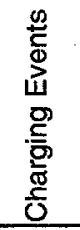 & 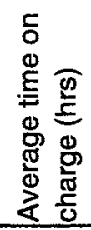 & 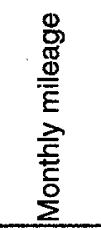 & 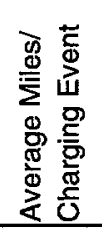 & 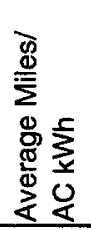 & 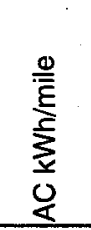 \\
\hline \multirow[t]{13}{*}{$23629^{*}$} & January & 31 & 105.23 & 136.56 & 34 & 4.07 & 625 & 18.38 & 2.58 & 0.39 \\
\hline & February & 28 & 103.08 & 218.82 & 29 & 3.37 & 760 & 26.21 & 2.36 & 0.42 \\
\hline & March & 31 & 103.63 & 159.82 & 19 & 4.86 & 461 & 24.26 & 1.75 & 0.57 \\
\hline & April & 30 & 46.92 & 84.98 & 8 & 9.13 & 156 & 19.50 & 1.18 & 0.85 \\
\hline & May & 31 & 34.92 & 118.20 & 21 & 2.88 & 315 & 15.00 & 2.06 & 0.49 \\
\hline & June & 30 & 59.35 & 85.66 & 16 & 3.09 & 744 & 46.50 & 5.13 & 0.19 \\
\hline & July & 31 & 153.08 & 208.96 & 35 & 2.49 & 740 & 21.14 & 2.04 & 0.49 \\
\hline & August & 31 & 89.88 & 95.26 & 17 & 2.59 & 438 & 25.76 & 2.37 & 0.42 \\
\hline & September & 30 & 150.84 & 167.52 & 33 & 2.53 & 531 & 16.09 & 1.67 & 0.60 \\
\hline & October & NA & NA & NA & NA & NA & 219 & NA & NA & NA \\
\hline & November & NA & NA & NA & NA & NA & 376 & NA & NA & NA \\
\hline & December & NA & NA & NA & NA & NA & 279 & NA & NA & NA \\
\hline & Totals & 122 & 453 & 557 & 101 & 2.68 & 3,327 & 27.37 & 2.80 & 0.427 \\
\hline \multirow[t]{13}{*}{$23630^{* *}$} & January & 31 & 139.28 & 92.6 & 35 & 2.27 & 464 & 13.26 & 2.00 & 0.50 \\
\hline & February & 28 & 45.69 & 29.67 & 20 & 1.74 & 93 & 4.65 & 1.23 & 0.81 \\
\hline & March & 31 & 78.3 & 91.8 & 18 & 4.40 & 72 & 4.00 & 0.42 & 2.36 \\
\hline & April & 30 & 60.5 & 54.97 & 22 & 2.17 & 90 & 4.09 & 0.78 & 1.28 \\
\hline & May & 31 & 97 & 97.7 & 23 & 3.34 & 164 & 7.13 & 0.84 & 1.19 \\
\hline & June & 30 & 157.79 & 278.44 & 62 & 2.02 & 654 & 10.55 & 1.50 & 0.40 \\
\hline & July & 31 & 369.31 & 461.95 & 84 & 2.58 & 1,251 & 14.89 & 1.50 & 0.664 \\
\hline & August & 31 & 372.31 & 455.19 & 90 & 2.43 & 1,210 & 13.44 & 1.46 & 0.684 \\
\hline & September & 30 & 154.13 & 218.7 & 44 & 2.68 & 562 & 12.77 & 1.51 & 0.663 \\
\hline & October & 31 & 82.89 & 116.46 & 31 & 1.59 & 200 & 6.45 & 1.00 & 0.997 \\
\hline & November & 15 & 25.78 & 17.02 & 13 & 1.37 & 20 & 1.54 & 0.47 & NA \\
\hline & December & 31 & 50.40 & $61: 77$ & 19 & 2.74 & 53 & 2.79 & 0.47 & NA \\
\hline & Totals & 168 & 1,162 & 1,548 & 324 & 2.11 & 3,897 & 9.94 & 1.24 & 0.682 \\
\hline $23631^{* *}$ & January & N/A & $\mathrm{N} / \mathrm{A}$ & N/A & $N / A$ & N/A & \multirow{5}{*}{$\begin{array}{c}509 \\
119 \\
71 \\
256 \\
113 \\
\end{array}$} & N/A & $N / A$ & N/A \\
\hline & February & N/A & N/A & N/A & $N / A$ & N/A & & N/A & $N / A$ & $\mathrm{~N} / \mathrm{A}$ \\
\hline & March & $\mathrm{N} / \mathrm{A}$ & N/A & N/A & $\mathrm{N} / \mathrm{A}$ & N/A & & N/A & $\mathrm{N} / \mathrm{A}$ & N/A \\
\hline & April & N/A & $\mathrm{N} / \mathrm{A}$ & N/A & $N / A$ & N/A & & N/A & N/A & N/A \\
\hline & May & N/A & N/A & N/A & $\mathrm{N} / \mathrm{A}$ & N/A & & N/A & N/A & N/A \\
\hline & June & N/A & N/A & $\mathrm{N} / \mathrm{A}$ & $\mathrm{N} / \mathrm{A}$ & N/A & 143 & $\mathrm{~N} / \mathrm{A}$ & N/A & N/A \\
\hline & July & 31 & 212.01 & 494.64 & 47 & 3.44 & 1,135 & 24.15 & 1.61 & 0.623 \\
\hline & August & 31 & 84.57 & 49.65 & 12 & 2.58 & 241 & 20.08 & 1.80 & 0.557 \\
\hline & September & 30 & 255.45 & 217.93 & 45 & 3.01 & 725 & 16.11 & 1.53 & 0.653 \\
\hline & October & 30 & 196.31 & 76.77 & 27 & 3.07 & 375 & 13.89 & 1.37 & 0.728 \\
\hline & November & 15 & 13.55 & 10.35 & 5 & 2.85 & 0 & 0.00 & 0.00 & NA \\
\hline & December & 24 & 39.71 & 67.73 & 18 & 2.85 & 3 & 0.17 & 0.03 & NA \\
\hline & Totals & 137 & 762 & 849 & 136 & 2.99 & 2.619 & 14.85 & 1.26 & 0.640 \\
\hline
\end{tabular}




\subsection{Vehicle Repair History}

Most of the S-10s acquired by SCE for fleet and accelerated reliability testing have had mechanical or electrical problems, particularly the three accelerated reliability vehicles. It became evident that most of the problems encountered early in the program were due to the way the vehicles were treated during transport from the factory and delivery to the customer. There was no record of what the state-of-charge of the batteries were when the vehicles left the factory. After a vehicle was received at the dealer, it was stored off-charge for several months while the paperwork was completed. In addition, it appeared that dealer personnel were neither well equipped nor properly trained to service electric vehicles. On several instances, vehicles displaying battery pack problems were sent to the dealer and were returned after inspection of conventional components such as brakes, while the real battery problem was ignored. For this reason, SCE personnel were trained by GM and eventually worked with GM engineers sent to SCE's EVTC to service the S-10s.

The main problem with the vehicles equipped with lead-acid batteries was low range - an average of between 30 and 35 miles on the Urban Pomona Loop. In addition, the three vehicles assigned for reliability testing $(23629,23630$ and 23631) had a leakage problem from the coolant reservoir (newer models had a better design).

When it was first delivered, vehicle 23631 would not charge and was sent back to the dealer. Vehicle 23629's range started to decline during testing. Vehicle 23630 was sent for repairs due to an electronic component failure during acceleration testing. Later, these two vehicles were sent back to the dealer with low range problems on several occasions. The average time the dealer had the vehicles for repairs was 2-3 weeks.

Because the problems with the vehicles were not being resolved, SCE contacted a GM regional field engineer. The field engineer replaced the battery packs and the defective coolant reservoirs on all three vehicles with low range. Any problems that surfaced after battery pack replacements were addressed directly by the field engineer. It should be noted that once the dealer was by-passed and GM became involved, a great deal of effort was invested by GM personnel to get the vehicles operational as quickly as possible. However, the time spent refining maintenance and repair processes at SCE made the vehicles unavailable for long periods of time.

After the battery packs were replaced in all three vehicles, average ranges were between 38 and 40 miles. However, it was noticed that the ranges would fluctuate from 30 to 45 miles during morning and afternoon driving cycles. The probable cause of these fluctuations was the ambient temperature (the vehicles performed poorly in colder ambient temperatures). For example, vehicle 23631, on January 22, 1998 , yielded 32.9 miles in the morning and 48 miles in the afternoon.

During February 1998, a substantial drop in performance was noted with vehicles 23630 and 23631 - to 30.9 miles and 27.5 miles respectively. Vehicle 23630 failed (all warning lights came on, and reduced performance mode started) during the last two tests. A manual disconnect was performed to reset the vehicle and to start charging. Vehicle 23631 also failed in the same manner during the baseline tests performed that month. Both vehicles failed with $10 \%$ state-of charge remaining. 
At GM's request, pulse and discharge tests were performed at the EVTC on all the reliability vehicles. The purpose of this testing was to identify defective modules in the recently installed battery packs. In addition, GM used the data collected to determine an action plan to repair other S-10s with the same problems. Defective modules were identified. Modules \#9, 10, 17,18 , and 24 were replaced in vehicle 23630 . Modules \#4, 5, 6, 7, 9, 14, 17, and 18 were replaced in vehicle 23631. In addition, the original module \#3 was substituted for module \#7 in vehicle 23631. After the replacement, the range recorded for vehicle 23630 returned to about 30 miles on average. However, this vehicle failed once with a state-of-charge of $3 \%$. It was determined that module \#9 might be the cause of the failure. On May 13, module \#9 was replaced for the second time.

It was determined that a charging problem that had damaged the vehicle's batteries caused the declining performance of vehicle 23631. This charging problem was detected at the end of the charge cycle. Instead of stopping, the charger went into a "full/support" mode continuously. The vehicle was sent to the dealer to replace the auxiliary power control module (APCM). However, after replacing the APCM, the problem persisted. The heating and thermal control module (HTCM) was replaced, but the problem continued. The charge port was switched from vehicle 23634 to 23631 . After charging for several hours, the vehicle completed its charge. It was then tested and reached a range of 44.3 miles.

In response to the concerns of some customers, Chevrolet Motor Division of General Motors issued service bulletins beginning in November 1997 that addressed the following problems:

- Coolant leaks from the propulsion system or fuel-fired heater system.

- Vehicle won't charge below $41^{\circ} \mathrm{F}$

- State-of-charge gage toggles between $\mathrm{E}$ and true reading.

- Cruise control inoperative.

- Reduced vehicle range when charged between $31^{\circ} \mathrm{F}$ and $37^{\circ} \mathrm{F}$.

On July 1, 1998, GM addressed these issues at the EVTC, and a new battery discharge test was performed to identify weak modules. The following procedures were performed on the three reliability vehicles, and the seven other S-10s in SCE's fleet:

- Reprogram battery pack control module (BPCM) and drive motor control module (DMCM)

- Replace HTCM

- Discharge traction battery and replace weak modules

- Replace the refrigerant label to specify the proper refrigerant oil number. 
To address customer complaints of low range, the BPCM was reprogrammed to turn the "Battery Life" light on at a lower (7\% user) state-of-charge (1/2 of the red zone), and the "Service Now" light on at $0 \%$ (user) state-of-charge ("E").

Vehicles 23629 and 23631 had battery modules replaced. Graphical representations of the discharge capacity tests for vehicles 23630 and 23631 are below (Figures 15 and 16). Note that the nominal capacity for the Delphi 19010704 VRLA battery is 48 Ah at the $\mathrm{C} / 2$ rate.

As mentioned previously, the three S-10s were used sparingly while awaiting repairs or replacement battery packs. At the end of 1998, the battery packs in vehicles 23630 and 23631 were replaced with used Delphi battery packs in better condition. After the change, vehicle 23630 did 45 miles on the Pomona Loop, but 23631 quit on the road after 28 miles, and will require further action. Vehicle 23629 is in service with the user, but under low mileage requirements.

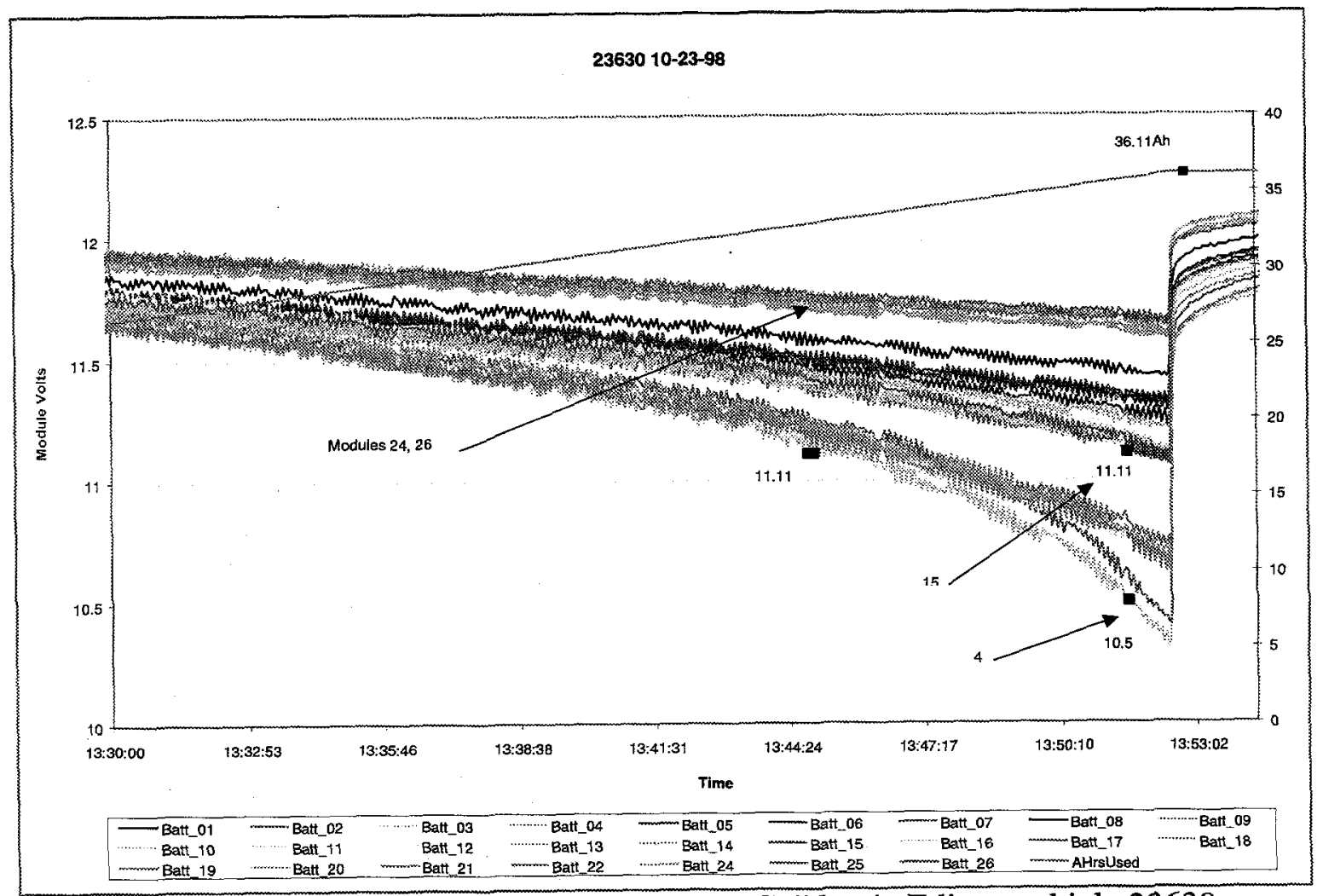

Figure 15. Discharge capacity test for Southern California Edison vehicle 23630 on October 23, 1998. 


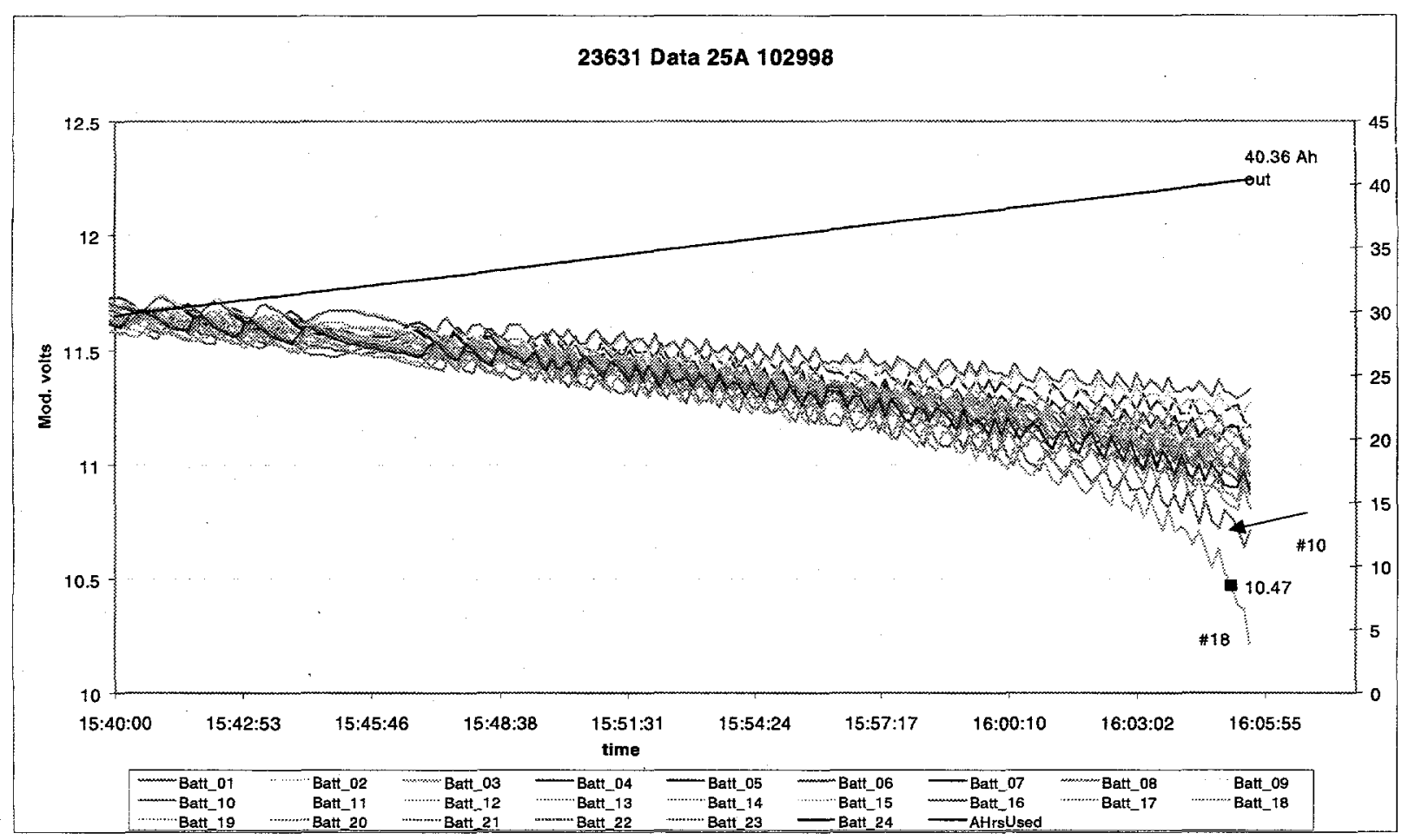

Figure 16. Discharge capacity test for Southern California Edison vehicle 23631 on October 23, 1998.

\subsection{Conclusions}

The S-10 Electric has acceleration, handling, and payload capabilities that match or exceed most electric vehicles currently on the market. The vehicle's driving qualities and the comfort of the driver are considered very good by most of those at SCE who have driven it. The problems SCE has experienced have been largely related to the Delphi 12 Volt battery modules. In that regard, GM has been diligently making an effort to replace battery packs of SCE's S-10s with more reliable and better performing lead-acid or nickel/metal-hydride batteries. Future leadacid battery equipped S-10s will have Panasonic modules. SCE has found that these batteries are more reliable, and give at least $20 \%$ more range. With the new batteries, and a reliable range of over 50 miles, SCE can recommend more widespread use of the S-10 Electric.

\subsection{Maintenance Logs}

\subsubsection{Vehicle 23629}

8/28/97 Vehicle 23629 was delivered to the EV Tech Center.

8/29/97 A baseline test was performed to determine its range. Range obtained: 35.4 miles.

9/3/97 Vehicle 23629 was placed under a special cycling regime to determine whether or not "gentle" cycling would increase the optimum vehicle range. The test consisted of cycling the vehicle twice a day at 20 miles per day from Monday to Thursday. 
On Friday, the vehicle was driven once to its full range. This regime was performed for a month.

10/3/97 After a month of "gentle" cycling, the range did not improve. The vehicle's range decreased to 28 miles.

10/14/97 After contacting GM's regional engineer, SCE followed special charging instructions for 23629 to determine any improvement in the vehicle's range.

10/16/97 The range did not improve. The vehicle was sent back to the dealer for repairs.

10/24/97 Vehicle 23629 was returned from the dealer. Repairs were completed.

10/27/97 A baseline test was performed; range obtained: 34.6 miles. Vehicle failed with $30 \%$ SOC left on the battery pack. Awaiting instructions from GM.

10/29/97 Under instructions from GM, SCE removed the manual disconnect for 24 hours.

10/30/97 The manual disconnect was replaced, and the vehicle was put on charge.

10/31/97 Vehicle failed during a baseline test after 14.4 miles. Vehicle did not respond after pulling over. SOC: $50 \%$.

11/3/97 Vehicle was sent to the dealer for repairs.

11/14/97 After meeting with GM, SCE concluded that all of the vehicles' battery packs $(23629,23630$, and 23631) would be replaced at the EV Tech Center. In addition, a new coolant reservoir will also be installed in each vehicle, since leaks were found on the current reservoir.

11/21/97 Vehicle 23629 was returned from the dealer; module \#23 was defective. No repairs were performed.

11/25/97 A new battery pack and a redesigned coolant reservoir were installed. All the systems were checked for any malfunction. No malfunctions were found.

11/26/97 A baseline test was performed; range obtained 40 miles.

1/19/98 Range test. Range: 42.3 miles

1/20/98 Range test. Starting time: 8:30 Range: 41 miles

Range test. Starting time: 14:15 Range: 43.2 miles

1/21/98 Range test. Starting time: 7:30 Range: 32.4 miles. Vehicle failed as soon as the driver pulled over to the charging station. Vehicle was not accepting charge; "check vehicle" message was displayed from the charger. Vehicle was able to reset and charge after performing a manual disconnect procedure. 
1/22/98 Range test. Starting time: 9:15. Range: 44.9 miles.

1/23/98 Range test. Starting time: 8:15. Range: 46.5 miles.

1/26/98 Range test. Starting time: 7:07. Range: 41 miles.

Vehicle was driven from EV Tech Center to user's home. Starting time: 16:15. Miles driven: 33.4 miles. SOC remained: $49 \%$

1/27/98 Vehicle driven from user \#1 home to EV Tech Center. Starting time: 6:15. A short range test was performed to use the remaining charge. Miles driven: 43 miles.

Vehicle driven from EV Tech Center to the user \#1 home. Starting time: 15:30. Miles driven: 33.3 miles. SOC remained: $50 \%$

1/28/98 Vehicle driven from user \#1 home to EV Tech Center. Starting time: 6:30. A short range test was performed to use the remaining charge. Miles driven: 39.1 miles.

Vehicle driven from EV Tech Center to user \#1 home. Starting time: 16:00. Miles driven: 33.6 miles. SOC remained: 50\%.

1/29/98 Vehicle driven from user \#1 home to EV Tech Center. Starting time: 6:30. A short baseline test was performed to use the remaining charge. Miles driven: 37.4 miles.

Vehicle driven from EV Tech Center to user \#1 home. Starting time: 15:45. Miles driven: 29.3 miles. SOC remained: $50 \%$.

1/30/98 Vehicle driven from user \#1 home to EV Tech Center. Starting time: 6:15. A short baseline test was performed to use the remaining charge. Miles driven: 41.7 miles.

Vehicle driven from EV Tech Center to user \#1 home. Starting time: 15:30. Miles driven: 29.3 miles. SOC remained: $50 \%$.

$2 / 2 / 98$

Vehicle driven from user \#1 home to EV Tech Center. Starting time: 6:30 Miles driven: 33.3 miles. Raining condition. Probable cause of shorter range: Use of auxiliary loads, and vehicle's battery pack was not cycled over the weekend. Baseline test. Starting time: 13:45 Range: 38.9 miles.

2/4/98 Range test. Starting time: 9:00. Range: 35.3 miles.

Vehicle driven from EV Tech Center to user \#1 home. Starting time: 16:00. Miles driven: 33.3 miles. SOC remained: $39 \%$. 
2/5/98 Vehicle driven from user \#1 home to EV Tech Center. Starting time: 6:15. A short range test was performed to use the remaining charge. Miles driven: 38.1 miles.

2/9/98 Range test. Range: 27.4 miles

2/11/98 Range test. Range: 37.6 miles

Range test. Range: 33.5 miles

2/12/98 Range test. Range: 38.5 miles

Range test. Range: 34.8 miles

2/13/98 Range test. Range: 33.9 miles

2/17/98 Range test. Range: 31.4 miles

2/18/98 Range test. Range: 31.9 miles

$2 / 19 / 98$ to

$3 / 6 / 98$

The vehicle was driven to its maximum range at least once a day. The average vehicle range was 34 miles per charge.

3/10/98 A discharge test was performed at the request of GM.

3/25/98 Vehicle's battery pack was exchanged with vehicle 23631 in order to find a possible charging malfunction on vehicle 23631 .

3/26/98 Baseline test. Range: 26.8 miles. Vehicle failed (Service Now and Batt Life lights on) with battery pack from vehicle 23631 at 26.1 miles. Following data was obtained with the scan tool:

\begin{tabular}{lll} 
& \multicolumn{1}{l}{ Start } & Stop \\
\cline { 2 - 3 } Pack capacity & $48 \mathrm{Ah}$ & $48 \mathrm{Ah}$ \\
Pack capability & $48.97 \mathrm{Ah}$ & $18.89 \mathrm{Ah}$ \\
Cumulative charge & $2411 \mathrm{Ah}$ & $2417 \mathrm{Ah}$ \\
Cumulative discharge $1824 \mathrm{Ah}$ & $1869 \mathrm{Ah}$ \\
Ah used & $0.04 \mathrm{Ah}$ & $29.11 \mathrm{Ah}$ \\
Self discharge & $0.0 \mathrm{Ah}$ & $0.0 \mathrm{Ah}$
\end{tabular}


4/7/98 Static discharge test at $25 \mathrm{~A}$

4/8/98 Auxiliary battery was exchanged with vehicle 23631 in order to determine the cause of the charging problem.

4/20/98 Vehicle's battery pack exchanged back to the original vehicle.

4/22/98 Baseline test. Range: 37.8 miles. Following data was obtained with the scan tool:

$$
\text { Start Stop }
$$

Pack capacity $\quad 48 \mathrm{Ah} \quad 48 \mathrm{Ah}$

Cumulative charge $\quad 4329 \mathrm{Ah} \quad 4336 \mathrm{Ah}$

Cumulative discharge $4035 \mathrm{Ah} \quad 4077 \mathrm{Ah}$

Ah used $\quad 0.0 \mathrm{Ah} \quad 36.02 \mathrm{Ah}$

Self discharge $\quad 0.1 \mathrm{Ah} \quad 0.1 \mathrm{Ah}$

7/1/98 GM upgrades at EVTC: reprogrammed BPCM and DMCM, replaced HTCM. Battery discharge test; module 25 replaced.

10/1/98 User sent vehicle to Pomona due to low range ( $<15 \mathrm{mi}$.). Did discharge procedure: 3 modules low but within spec.

10/14/98 Range test: $40.6 \mathrm{mi}$. Return to user.

\subsubsection{Vehicle 23630}

8/28/97 Vehicle 23630 was delivered to the EV Tech Center.

8/29/97 A baseline test was performed. Range obtained: 42.7 miles.

9/3/97 Vehicle 23630 was assigned for a full vehicle characterization.

10/8/97 Vehicle 23630 failed during an acceleration test. An electronic component burned out. The vehicle was sent back to the dealer for repairs.

10/24/97 Vehicle 23630 was returned from the dealer. Repairs were completed.

10/27/97 A baseline test was performed; range obtained: 24.4 miles.

10/28/97 Range test: 37.6 miles.

10/31/97 Vehicle 23630 was driven from user's (D.D.) house to the EV Tech Center; the vehicle reached $0 \%$ SOC after 30 miles from a 35 mile trip. 
11/3/97 Vehicle put on cycling program of about 25 miles per day.

11/14/97 After meeting with GM, SCE concluded that all the vehicles' battery packs $(23629,23630$, and 23631) will be replaced at the EV Tech Center. In addition, a new coolant reservoir will also be installed in each vehicle since leaks were found on the current reservoir.

11/26/97 A new coolant reservoir was installed.

12/4/97 A new battery pack was installed. No malfunctions were found.

12/5/97 A baseline test was performed. Range obtained: 38 miles.

1/7/98 Vehicle 23630 was driven from D. Douglas' house to EV Tech Center. Distance Traveled: 32.1 miles; SOC remained: $5 \%$. Not recommended for reliability test.

1/20/98 Range test. Range: 36.9 miles.

1/21/98 Range test. Start time: 7:30 Range: 41.4 miles.

Range test. Start time: 12:30 Range: 39.4 miles.

1/22/98 Range test. Start time: 7:45 Range: 43.8 miles.

1/23/98 Range test. Start time: 7:30 Range: 36.6 miles.

Range test. Start time: 13:00 Range: 39.7 miles.

1/26/98 Range test. Start time: 11:45 Range: 34.2 miles.

1/27/98 Range test. Start time: 8:45 Range: 39 miles.

1/28/98 Range test. Start time: 8:00 Range: 35.9 miles.

1/29/98 Range test. Start time: 9:30 Range: 29.9 miles. Rain

1/30/98 Range test. Start time: 8:00 Range: 33.2 miles.

2/2/98 Range test. Start time: 10:00 Range: 30.9 miles. Vehicle failed before pulling over to the charging station. Vehicle was not accepting charge; "check vehicle" message was displayed from the charger. After performing a manual disconnect, the vehicle was able to reset and charge.

2/4/98 Range test. Start time: 7:30. Range: 27.5. Vehicle failed at 26.1 miles, "service now" and "battery life" lights on, reduced performance; 20-25 mph. "Service now" light turned on and off on several occasions. Vehicle was able to return to the EV Tech Center. Vehicle was not accepting charge; "check vehicle" message was displayed from the charger. After performing a manual disconnect, the vehicle was able to reset and charge. 
Range test. Start time: 7:45. Range: 29 miles. Vehicle failed. "Service now" and "Battery Life" lights on. Vehicle was able to return to the EV Tech Center.

Vehicle was not accepting charge; "check vehicle" message was displayed from the charger. After performing a manual disconnect, the vehicle was able to reset and charge.

$2 / 10 / 98$

Vehicle was sent to the dealer for repairs.

$2 / 13 / 98$

Vehicle returned from the dealer at the request of GM's field engineer. Repairs will be performed at EVTC with his assistance.

$3 / 10 / 98$

A discharge and pulse test was performed at request of GM.

$3 / 18 / 98$

Range test: Range 29.5 miles

$3 / 26 / 98$

Range test. Range: 24.2 miles. Vehicle failed (Service Now and Batt Life lights on) with $7 \%$ SOC remaining. Following data was obtained with the scan tool:

Start Stop

Pack capacity $\quad 48 \mathrm{Ah} \quad 48 \mathrm{Ah}$

Cumulative charge $1076 \mathrm{Ah} \quad 1081 \mathrm{Ah}$

Cumulative discharge $969 \mathrm{Ah} \quad 999 \mathrm{Ah}$

Ah used $\quad 1.10 \mathrm{Ah} 26.74 \mathrm{Ah}$

Self discharge $\quad 0.0 \mathrm{Ah} \quad 0.0 \mathrm{Ah}$

4/7/98 Static discharge test at $25 \mathrm{~A}$

4/20/98 Module replacement of \# 9, 10, 17, 18 and 24

4/22/98 Range test. Range: 32 miles. Vehicle failed at 3\% SOC (Service Now and Batt Life lights on) No power steering. Weak module \#9. Following data was obtained with the scan tool:

$\begin{array}{lll} & \text { Start } & \text { Stop } \\ \text { Pack capacity } & 48 \mathrm{Ah} & 48 \mathrm{Ah} \\ \text { Pack temperature } & 80 \mathrm{~F} & 80 \mathrm{~F} \\ \text { Cumulative charge } & 1187 \mathrm{Ah} & 1193 \mathrm{Ah} \\ \text { Cumulative discharge } & 1046 \mathrm{Ah} & 1082 \mathrm{Ah} \\ \text { Ah used } & 0.96 \mathrm{Ah} & 31.48 \mathrm{Ah} \\ \text { Self discharge } & 0.0 \mathrm{Ah} & 0.0 \mathrm{Ah}\end{array}$


4/23/98 Range test. Range: 30 miles. Test stopped at 9\% SOC. Following data was obtained with the scan tool:

$\begin{array}{lll} & \text { Start } & \text { Stop } \\ \text { Pack capacity } & 48 \mathrm{Ah} & 48 \mathrm{Ah} \\ \text { Pack temperature } & 79 \mathrm{~F} & 79 \mathrm{~F} \\ \text { Cumulative charge } & 1226 \mathrm{Ah} & 1230 \mathrm{Ah} \\ \text { Cumulative discharge } & 1082 \mathrm{Ah} & 1115 \mathrm{Ah} \\ \text { Ah used } & 0.96 \mathrm{Ah} & 29.09 \mathrm{Ah} \\ \text { Self discharge } & 0.0 \mathrm{Ah} & 0.0 \mathrm{Ah}\end{array}$

5/12/98 Module \#9 replaced.

7/1/98 GM upgrades at EVTC: reprogrammed BPCM and DMCM, replaced HTCM. Battery discharge test.

9/24/98 User reports low range (17 mi.). Did discharge test: mod. 21, 26 replaced.

10/7/98 Range test: $35 \mathrm{mi}$.

10/15/98 Vehicle shut down at $28 \mathrm{mi}$. Tow to Pomona.

10/20/98 Vehicle shut down at $29 \mathrm{mi} . / 25 \%$ SOC on the Pomona Loop. Tow to Pomona. Vehicle needs 7 modules.

12/2/98 Seven modules replaced at the EVTC.

12/3/98 Pomona Loop range test: "Power Limit" at 23.0 miles (SOC 35\%), "Batt Life" light on at 23.7, "Service Now" at 25.5 miles, final SOC: $32 \%$. After charging, vehicle is parked awaiting new battery pack.

1/5/99 New (used) pack installed (Delphi) odo 5815.

1/6/99 Range test 45 miles. 


\subsubsection{Vehicle 23631}

8/28/97 Vehicle 23631 was delivered to the EV Tech Center. Vehicle was not accepting charge; "check vehicle" message was displayed from the charger. Vehicle was sent back to the dealer.

9/xx/97 Vehicle 23631 was received back from the dealer. Repairs were completed.

9/10/97 A baseline test was performed; range obtained 43.3 miles.

9/30/ 97 Same charging problem. The vehicle does not charge more than $94 \%$ SOC. Also, "Service Vehicle" is displayed.

10/6/97 Vehicle 23631 was sent back to the dealer for repairs.

10/22/97 Vehicle 23631 was received back from the dealer. Repairs were completed.

10/24/97 A range test was performed; range obtained 38.8 miles.

10/30/97 Vehicle 23631 was driven to J. Smith house. Distance traveled: 41.5 miles; SOC remained: $16 \%$

10/31/97 Vehicle 23631 failed before returning to EV Tech Center after 33 miles; SOC $30 \%$.

11/7/97 A range test was performed; range obtained: 37.5 miles.

11/10/97 Vehicle 23631 was driven from R. Mok house to the EV Tech Center. The vehicle failed about one mile before reaching the EV Tech Center. SOC 20\%. Distance traveled 32.5 miles.

11/14/97 After meeting with GM, it was concluded that all the vehicles' battery packs $(23629,23630$, and 23631) will be replaced at the Tech Center. In addition, a new coolant reservoir will also be installed in each vehicle since leaks were found on the current reservoir.

11/26/97 A new coolant reservoir was installed.

12/4/97 A new battery pack was installed. No malfunctions were found.

12/5/97 A baseline test was performed on vehicle 23631. Range obtained: 40 miles.

1/14/98 Vehicle 23631 was driven from EV Tech Center to R. Mok house. Distance traveled 33.2 miles; SOC remained: $5 \%$. Vehicle failed after pulling over to the driveway. Vehicle was not accepting charge; "check vehicle" message was displayed from the charger. After performing a manual disconnect, the vehicle was able to reset and charge.

1/19/98 Range test. Range: 39.5 miles. 
1/20/98 Range test. Starting time: 10:15 Range: 40.7 miles.

Range test. Starting time: 15:30 Range: 37.7 miles.

1/22/98 Range test. Start time: 7:30 Range: 32.9 miles. Ambient temp. $45 \mathrm{~F}$

Range test. Start time: 1:15 Range: 48 miles. Ambient temp. $65 \mathrm{~F}$

1/23/98 Range test. Starting time: 10:36 Range: 46.2 miles.

1/26/98 Range test. Starting time: 13:00 Range: 41 miles.

1/27/98 Range test. Starting time: 10:30 Range: 37.8 miles. Vehicle failed after pulling over to the charging station. Vehicle was able to reset and charge.

1/28/98 Range test. Starting time: 9:30 Range: 35.8 miles.

1/29/98 Range test. Starting time: 8:00 Range: 34.9 miles. Rain

1/30/98 Range test. Starting time: 9:30 Range: 36.9 miles.

2/2/98 Range test. Starting time: 7:45 Range: 35.6 miles.

2/4/98 Range test. Starting time: 12:30 Vehicle failed at mile 29.7

"Service now" and "battery life" lights on. Reduced performance; 20-25 mph. Vehicle was able to pull over into a parking lot. A tow truck was called. SOC $10 \%$. Vehicle was able to charge without any problem. Unknown cause of vehicle failure.

2/5/98 Range test. Starting time: 7:45 Vehicle failed at mile 30.1 "Service now" and "battery life" lights on. Reduced performance; 20-25 mph. Vehicle was able to return to EV Tech Center. SOC 10\%. Vehicle was not accepting charge; "check vehicle" message was displaying from the charger. After performing a manual disconnect, the vehicle was able to reset and charge.

2/10/98 Vehicle was sent to the dealer for repairs.

2/13/98 Vehicle returned from the dealer at the request of GM's field engineer. Repairs will be performed at EVTC with his assistance.

3/10/98 A discharge and pulse test was performed at the request of GM.

3/18/98 Range test: Range 29 miles. Vehicle failed (Service Now and Batt Life light on) at mile 24.4; SOC $15 \%$. Vehicle was able to return at the EVTC at minimum power.

3/25/98 Vehicle's battery pack was exchanged to vehicle 23629 in order to find a possible charging malfunction. 
3/26/98 Range test. Range: 32.1 miles. Battery pack from vehicle 23629. Following data was obtained with the scan tool:

Start Stop

Pack capacity $\quad 48 \mathrm{Ah} \quad 48 \mathrm{Ah}$

Cumulative charge $\quad 4211 \mathrm{Ah} \quad 4217 \mathrm{Ah}$

Cumulative discharge $3947 \mathrm{Ah} \quad 3988 \mathrm{Ah}$

$\begin{array}{lll}\text { Ah used } & 0.01 \mathrm{Ah} & 34.41 \mathrm{Ah}\end{array}$

Self discharge $\quad 0.0 \mathrm{Ah} \quad 0.0 \mathrm{Ah}$

3/30/98 Vehicle was sent to the dealer to replace the APCM to solve a possible charging problem (full support mode does not stop).

4/7/98 Static discharge test at $25 \mathrm{~A}$.

4/8/98 Auxiliary battery was exchanged to vehicle 23629 to determine the cause of the vehicle's charging problem. Vehicle continues to present the same charging problem.

4/20/98 Battery pack exchanged back to the original vehicle.

4/22/98 Heating and thermal control module (HTCM) was replaced in order to solve the vehicle's charging problem.

5/5/98 Module replacement. \#4, 5, 6, 7, 9, 14, 17, 18. Module \# 7 was exchanged from the original \#3 module. Vehicle continues to present the same charging problem.

5/13/98 Charger port was exchanged from vehicle 23634 in order to determine the charging problem. Vehicle was able to complete charge; all systems are operational.

Range test. Range: 44.3 miles. Ambient Temp.: $58^{\circ} \mathrm{F}$

5/14/98 Range test. Range: 43.6 miles. Ambient Temp.: $60^{\circ} \mathrm{F}$

5/15/98 Range test. Range: 40 miles. Ambient Temp.: $62^{\circ} \mathrm{F}$ 
Following data was obtained with the scan tool:

\begin{tabular}{lll} 
& Start & Stop \\
\cline { 2 - 3 } Pack capacity & $48 \mathrm{Ah}$ & $48 \mathrm{Ah}$ \\
Cumulative charge & $244 \mathrm{Ah}$ & $251 \mathrm{Ah}$ \\
Cumulative discharge & $203 \mathrm{Ah}$ & $247 \mathrm{Ah}$ \\
Ah used & $0.01 \mathrm{Ah}$ & $37.2 \mathrm{Ah}$ \\
Self discharge & $0.1 \mathrm{Ah}$ & $0.1 \mathrm{Ah}$
\end{tabular}

6/25/98 After a drive of 30 miles, charger SOC read 93\%, and 98\% a few minutes later. Vehicle reached full after several hours.

7/1/98 GM upgrades at EVTC: reprogrammed BPCM and DMCM. Battery discharge test; module 4 replaced.

8/4/98 Vehicle sent to dealer for drive axle campaign and for low range (2030 miles).

8/12/98 Returned to EVTC. Battery pack was tested - no problem found. Vehicle would not start - returned to dealer.

8/24/98 Range test: 34.8 miles.

9/25/98 User reports low range (17 mi.). Did discharge test: module 16 replaced.

10/7/98 Range test: $30+$ mi. Vehicle needs 1 module.

12/2/98 Vehicle tested at EVTC by Alex Wong. No modules replaced.

12/3/98 Vehicle parked awaiting replacement battery pack.

1/6/99 New used Delphi pack installed. Range test 28 miles, quit on road. 


\section{DRIVER QUESTIONNAIRE COMBINED RESULTS}

A Driver Questionnaire was filled out by 27 of the S-10 drivers at Southern California Edison and Electric Transportation Applications. Figure 17 shows the complete questionnaire. Table 4 provides the results of the general question section of the Questionnaire. Of the total general questions asked (Table 4), 61\% of the 150 responses were favorable (SA or A), while only $18 \%$ were unfavorable (D or SD). Question number 7 (Table 5), which asked the drivers' for their vehicle preference, did not indicate as positive a response for electric vehicles; $54 \%$ of the drivers preferred gasoline power vehicles exclusively.

The responses for the Driveability, Controls and Gauges, Interior, and Charging Sections are not provided, as they tend to be much more subjective. For instance, responses concerning how adequate the heater works by drivers in Phoenix or Southern California does not provide information that accurately reflects how well the heater would work in the cooler climates experienced in the rest of the United States.

Table 4. General questions section responses from the Electric Vehicle Driver Questionnaire, as provided by Southern California Edison and Electric Transportation Application drivers.

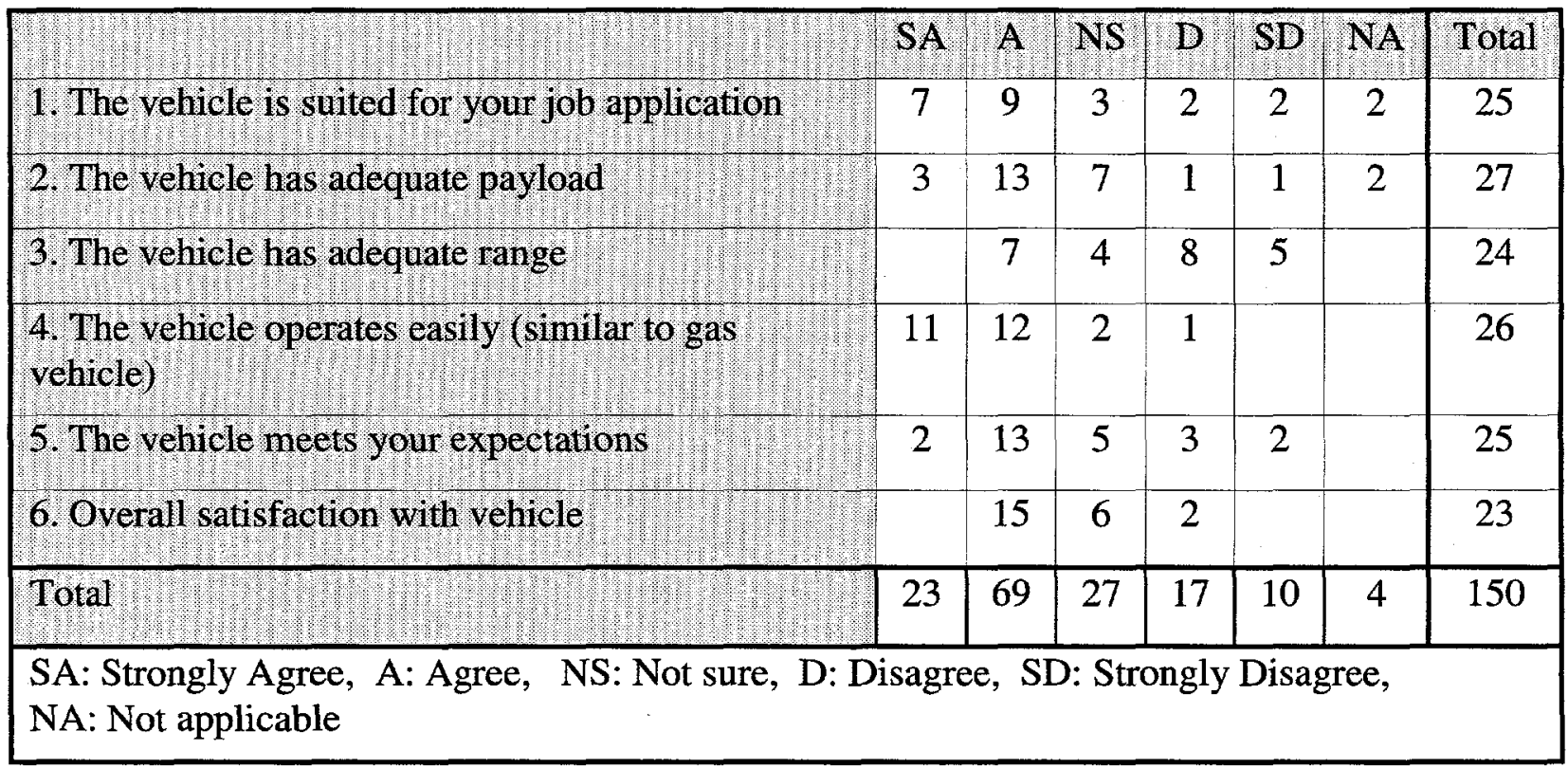

Table 5. Electric Vehicle Driver Questionnaire responses to the vehicle preference question from Southern California Edison and Electric Transportation Application drivers.

\begin{tabular}{|c|c|c|c|c|}
\hline - & Electric & Gasoline & Either & Total \\
\hline $\begin{array}{l}\text { 7. If you had to choose between this vehicle or a } \\
\text { similar gasoline vehicle, which would you select? }\end{array}$ & 6 & 14 & 6 & 26 \\
\hline
\end{tabular}


Figure 17. Sample Electric Vehicle Driver Questionnaire.

\section{ELECTRIC VEHICLE DRIVER QUESTIONNAIRE}

DRTER NAME: J.W.SM/TH DATE: $8 / 28 / 47$

JOB APPLICATION: TEST ENG/NGLC LOCATION: POMONA

VEHICLE \#: 23630 VEHICLE MODEL: CHEVOLET $S-10$

\section{DRIVEABILITY}

1. The vehicte feels stable in wet weather conditions

2. The vehicle feels stable at highway speeds

3. The vehicle steering is responsive on the road

4. The vehicie acceleration is adequate

5. The venicle braking is responsive CONTROLS AND GAUGES

1. The temperature controls are easy to operate

2. The "state-of charge" gauge was helpful

3. The "range remaining" gauge was helpful

\section{INTERIOR}

1. The heater provides adequate heat

2. The air conditioner provides adequate cooling

3. The vehicle is free from trefroad noise

4. The interior is free from excessive accessory noise

\section{CHARGING}

1. The refueling (charge) process is simple

2. The vehicle charges adequately (full in the morning)

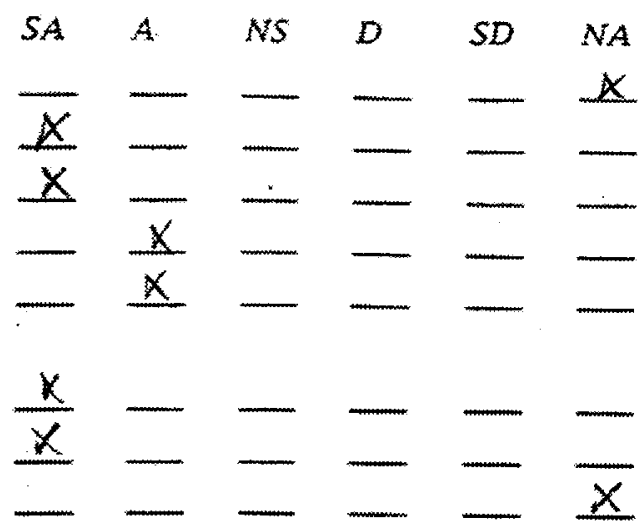
GENERAL

1. The vehicle is suited for your job application

2. The vehicle has adequate payload

3. The vehicle has adequate range

4. The vehicle operates easily (similar to gasoline vehicle)

5 . The vehicle meets your expectation

6. Overall satisfaction with vehicle

7. If you had to choose between this vehicle or a similar gasoline vehicle, which would you select?

$$
\text { Electric Vehicle Gasoline Vehich Either (Circle One) }
$$

\section{COMMENTS}

What did vou like best? $-\Delta R$ WhS eAsity 6000 powh

What did voulikeleas? ThE RAWGE is TOP LOW

SA: Strongly Agree; A; Agree; NS: Not Sure; D: Disagree; SD: Strongly Disagrec; NA: Not Applicable 


\section{S-10 TESTING FACT SHEETS}

The following pages contain the S-10 Fact Sheets for the Baseline Performance (EVAmerica) testing performed by ETA and the Pomona Loop testing performed by SCE. These Fact Sheets and Fact Sheets for other electric vehicles tested by the Field Operations Program and its testing partners can be viewed at the Program's web site: http://ev.inel.gov/sop. 


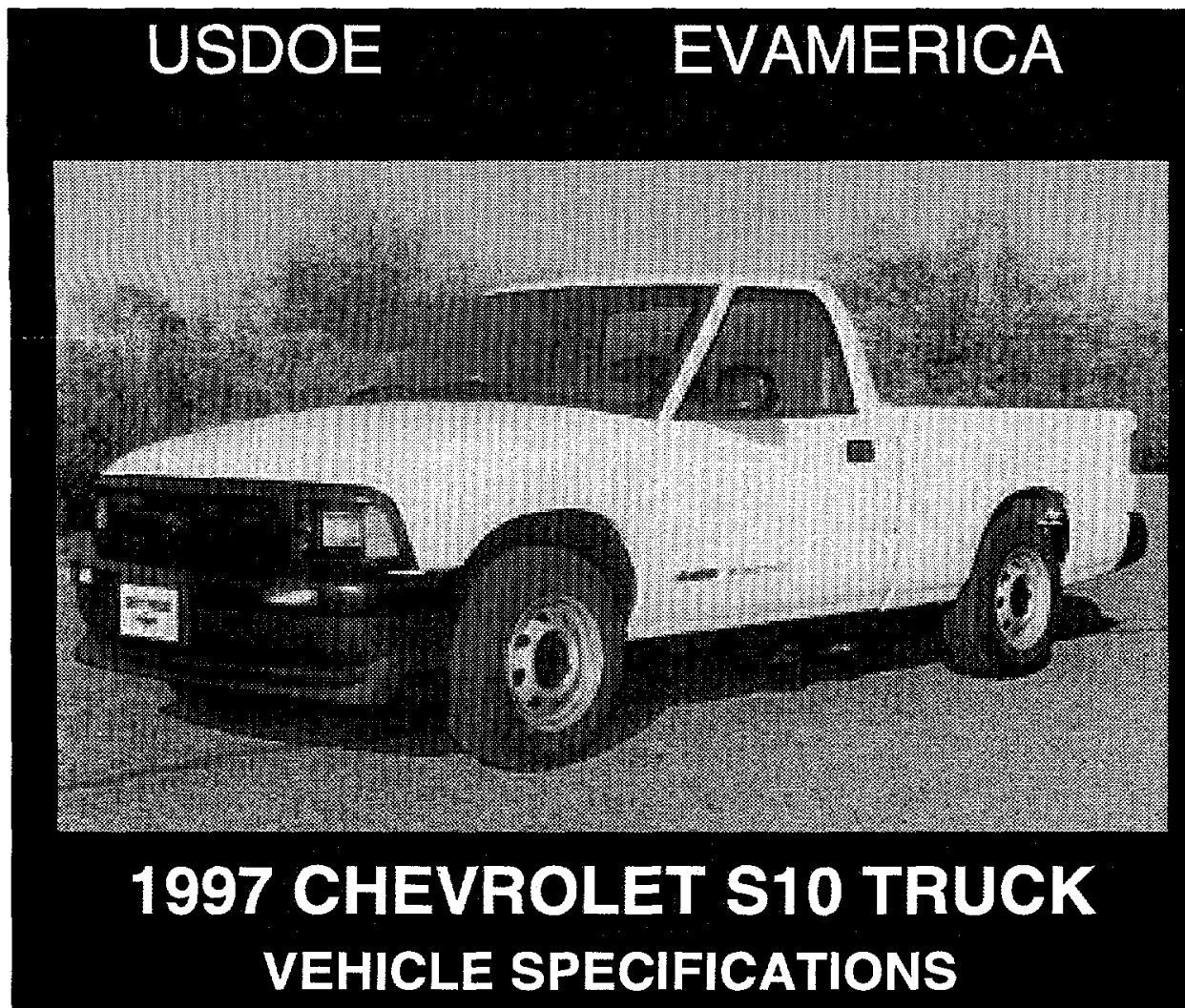

\section{PURPOSE-BUILT VEHICLE}

Base Vehicle: 1997 Chevrolet S-10

VIN: 1GCDE14H4V80003EX

Seatbelt Positions: Three

Standard Features:

$\begin{array}{ll}\text { Heat Pump Climate } & \text { Power Steering } \\ \text { Control System } & \text { Power Brakes } \\ \text { Auxiliary Diesel Fuel } & \text { Anti-Lock Brakes } \\ \text { Fired Heater (Only } & \text { Front Disk Brakes } \\ \text { operates Below 40 F) } & \text { Regenerative Braking } \\ \text { Cruise Control } & \text { Drivers Side Air Bags } \\ \text { Tilt Steering Wheel } & \text { AM/FM Stereo Radio } \\ \text { Front Wheel Drive } & \text { Half-Bed Tonneau } \\ & \text { Cover }\end{array}$

\section{BATTERY}

Manufacturer: Delphi Energy

Type: Valve Regulated Lead Acid

Number of Modules: 26

Weight of Module: $19 \mathrm{~kg}$

Weight of Pack(s): $575 \mathrm{~kg}$

Pack Locations: Underbody

Nominal Module Voltage: $12 \mathrm{~V}$

Nominal System Voltage: $312 \mathrm{~V}$

Nominal Capacity (C/2): $48 \mathrm{Ah}$

\section{WEIGHTS}

Design Curb Weight: 4,300 lb

Delivered Curb Weight: $4,199 \mathrm{lb}$

Distribution F/R: $48 / 52 \%$

GVWR: $5,150 \mathrm{lb}$

GAWR F/R: $2,700 / 2,900 \mathrm{lb}$

Payload: $951 \mathrm{lb}$

Performance Goal: $600 \mathrm{lb}$

\section{DIMENSIONS}

Wheelbase: 108.3 inches

Track F/R: 57.2/54.9 inches

Length: 188.9 inches

Width: 67.8 inches

Height: 62.4 inches

Ground Clearance: 5.0 inches at GVWR

Performance Goal: 5.0 inches at GVWR

\section{CHARGER}

Location: Off-Board

Type: Delco Electronics Inductive $6.6 \mathrm{~kW}$ Input Voltages: 165 to $260 \mathrm{VAC}$

\section{TIRES}

Tire Mfg: Uniroyal

Tire Model: Tigerpaw AWP Radial

Tire Size: P205/75R15

Tire Pressure F/R: 51/51 psi

Spare Installed: No
ACCELERATION 0-50 $\mathrm{mph}$

At $100 \%$ SOC: $9.75 \mathrm{sec}$

At $50 \%$ SOC: $10.35 \mathrm{sec}$

Max. Power: $104.3 \mathrm{~kW}$

Performance Goal: $13.5 \mathrm{sec}$ at $50 \%$ SOC

MAXIMUM SPEED @ $50 \%$ SOC $^{1}$

At $1 / 4$ Mile: $67.6 \mathrm{mph}$

At 1 Mile: $69.3 \mathrm{mph}$

Performance Goal: $70 \mathrm{mph}$ in one mile

CONSTANT SPEED RANGE @ $45 \mathrm{mph}$

Range: 60.4 miles

Energy Used: $12.99 \mathrm{kWh}$

Average Power: $9.70 \mathrm{~kW}$

Efficiency: $215 \mathrm{Wh} / \mathrm{mile}$

Specific Energy: $22.2 \mathrm{Wh} / \mathrm{kg}$

CONSTANT SPEED RANGE @ $60 \mathrm{mph}$

Range: 38.8 miles

Energy Used: $11.93 \mathrm{kWh}$

Average Power: $18.30 \mathrm{~kW}$

Efficiency: $307 \mathrm{Wh} / \mathrm{mile}$

Specific Energy: $20.7 \mathrm{Wh} / \mathrm{kg}$

DRIVING CYCLE RANGE

Range per SAE J1634: 43.8 miles

Energy Used: $12.81 \mathrm{kWh}$

Average Power: $6.98 \mathrm{~kW}$

Efficiency: $292 \mathrm{Wh} / \mathrm{mile}$

Specific Energy: $22.3 \mathrm{Wh} / \mathrm{kg}$

Performance Goal: 60 miles

BRAKING FROM $60 \mathrm{mph}$

Controlled Dry: 182.2 feet

Controlled Wet: 216.3 feet

Panic Wet: 192.1 feet

Course Deviation: 0.0 feet

\section{HANDLING}

Avg Time@ 90\% SOC: $56.2 \mathrm{sec}$ Avg Time@ @ 50\% SOC: $55.8 \mathrm{sec}$ Avg Time@ 20\% SOC: $55.5 \mathrm{sec}$ Avg S-10 ICE Time: $58.3 \mathrm{sec}^{2}$

GRADEABILITY (Calculated) Maximum Speed @ 3\%: $68.0 \mathrm{mph}$ Maximum Speed @ 6\%: $66.5 \mathrm{mph}$ Maximum Grade: $36.4 \%$

Time on $3 \%$ Grade: $10 \mathrm{~min} 3 \mathrm{sec}^{3}$

Performance Goal: 15 Min from 50\% SOC

\section{CHARGING EFFICIENCY}

Efficiency: $470 \mathrm{Wh}-\mathrm{AC} / \mathrm{mile}$

Energy Cost @10 $/ \mathrm{kWh:4.70 \phi /mile}$

\section{CHARGER}

Max Charger Ground Current: $<0.01 \mathrm{~mA}$ Max Battery Leakage Current: $<0.01 \mathrm{~mA}$ Max DC Charge Current: 16.9 Amps Max AC Charge Current: 19.4 Amps Pwr Factor@ Max Current: 0.97 THD(I) @ Max Current: 7.70\% Peak Demand: $6.59 \mathrm{~kW}$

Time to Recharge: $5 \mathrm{Hrs} 15 \mathrm{~min}$ Performance Goal: 8 hours 
The Chevrolet S10 Pickup meets the following EV America Minimum Requirements:

1. The vehicle has a payload of at least 400 pounds.

2. The OEM GVWR has not been increased.

3. The OEM GAWRs have not been increased.

4. Seating capacity is a minimum of 2 passengers.

5. A battery recycling plan has been provided.

6. The electrical conversion materials have not intruded upon the OEM passenger space.

7. The vehicle has a parking mechanism or parking brake as required by 49 CFR 571.105.

8. The vehicle has a minimum range between charges of at least 50 miles when loaded with two 166-pound occupants and operated at a constant $45 \mathrm{mph}$.

9. The vehicle manufacturer has certified that this vehicle complies with the Federal Motor Vehicle Safety Standards (FMVSS) applicable on the date of manufacture.

10. The vehicle manufacturer's proposal states that batteries and/or battery enclosures do not intrude into the passenger compartment during or following a frontal barrier, rear barrier, or side-impact collision and roll-over.

11. Batteries comply with requirements of SAE J1718, and are so labeled.

12. The vehicle manufacturer has certified concentrations of explosive gases in the battery box do not exceed $25 \%$ of the Lower Explosive Limit (LEL) during and following normal or abnormal charging and operation of the vehicle.

13. The battery charger is capable of recharging the main propulsion battery in less than 12 hours when recharging at $208 \mathrm{~V}$ single phase $40 \mathrm{~A}$ maximum.

14. The vehicle manufacturer has certified the charger is capable of accepting input voltages of 208 VAC and 240 VAC single phase 60 Hertz, with a tolerance of $-13 \%+6 \%$ of rated voltage. Charger input current input current is compatible with 40 amp circuit breakers, and complies with requirements of SAE $\mathbf{J} 1773$.

15. The charger has a true power factor of .95 or greater and a harmonic distortion of $<=20 \%$ (current at rated load).

16. The charger is fully automatic, determining when "end of charge" conditions are met and transitioning into a mode that maintains the main propulsion battery at a full state of charge while not overcharging when continuously left on charge.

17. Vehicle does not contain exposed conductors, terminals, contact blocks or devices of any type that create the potential for personnel to be exposed to 50 volts or greater.

18. Vehicles are accompanied with manuals for parts, service, operation and maintenance, interconnection wiring diagrams and schematics.

19. The vehicle has a state of charge indicator for the main propulsion batteries.

20. Propulsion power is isolated from the vehicle chassis and battery leakage current from propulsion system to vehicle chassis is less than 0.5 MIU under static conditions.

21. Charging circuits are isolated from the vehicle chassis such that ground currents from a grounded chassis during charging does not exceed 5 $\mathrm{mA}$.

22. Replacement tires are commercially available to the end user.

23. The vehicle has the following interlocks:

a) The controller does not energize in any drive selector position other than "Park" or "Neutral"

b) The start key is removable only in the "Off" position, with the drive selector in "Park"

c) The controller does not initially energize or excite with a preexisting accelerator input.

24. The vehicle manufacturer has certified this vehicle complies with FCC requirements for unintentional emitted electromagnetic radiation, as identified in 47 CFR 15, Subpart B, "Unintentional Radiators."

25. The vehicle manufacturer has certified failure of a battery or battery pack is deemed to have occurred if the actual battery capacity is not at least $80 \%$ of the nominal ampere hour capacity.

26. The vehicle is equipped with an automatic disconnect and a manual service disconnect for the main propulsion batteries which are clearly labeled.

27. The charging system is compatible with Personnel Protection Systems per SAE J1773.

28. Material Safety Data Sheets (MSDS) for all on-board batteries have been supplied.

29. The manufacturer has identified the level of charge below which the batteries should not be discharged and how the controller automatically limits battery discharge below this level.

30. The vehicle manufacturer has verified that the methods(s) of charging the propulsion batteries and the charging algorithm have be reviewed and approved by the battery manufacturer.

31. The charger is capable of meeting the requirements of Section 625 of the National Electric Code (NEC).

32. The vehicle complies with the requirements of 49 CFR 571.301 for fuel-fired heaters.

33. The vehicle has an on-board Battery Energy Management System (BMS).

This information was prepared with the support of the U.S. Department of Energy (DOE) Award No. DE-FC-07-91ID-13079. However, any opinions, findings, conclusions or recommendations expressed herein are those of the author(s) and do not necessarily reflect the views of DOE. 


\section{Electric Vehicle Performance Characterization Summary}

\section{ELECTRIC TRANSPORTATION Division}

\section{CHEVROLETS

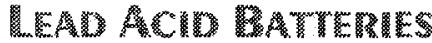 \\ SEPBTEMERT 1997}

Urban Range

(ON URBAN POMONA LOOP - SEE OTHER SIDE FOR MAP)

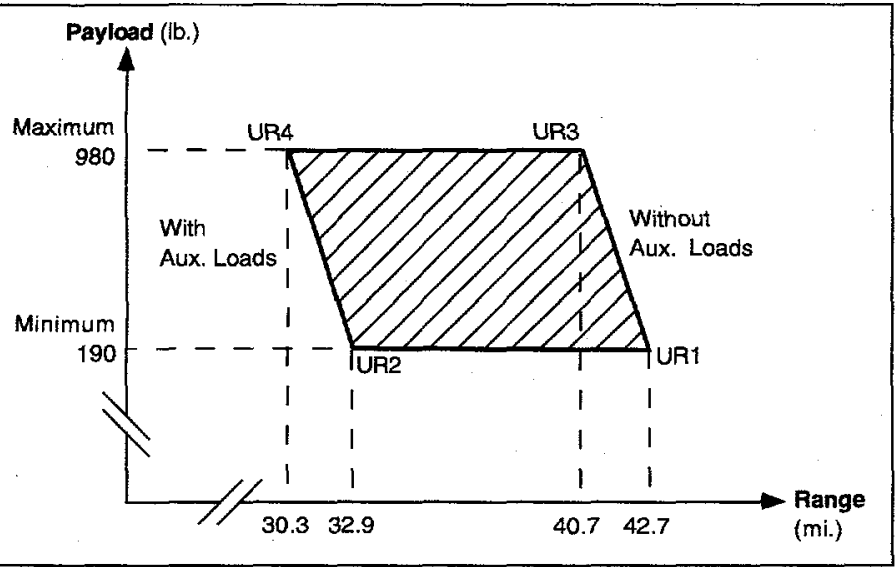

\begin{tabular}{|c|c|c|c|c|}
\hline TEST & UR1 & UR2 & UR3 & UR4 \\
\hline PAYLOAD (LB) & 190 & 190 & 980 & 980 \\
\hline AC KWHRECHARGE & 16.93 & 17.59 & 19.21 & 20.24 \\
\hline AC KWHMI & 0.396 & 0.535 & 0.472 & 0.668 \\
\hline RANGE (M) & 42.7 & 32.9 & 40.7 & 30.3 \\
\hline AVG. AMBIENT TEMP. & $77^{\circ} \mathrm{F}$ & $91^{\circ} \mathrm{F}$ & $89^{\circ} \mathrm{F}$ & $90^{\circ} \mathrm{F}$ \\
\hline
\end{tabular}

State of Charge Meter

(Urban Range Test)
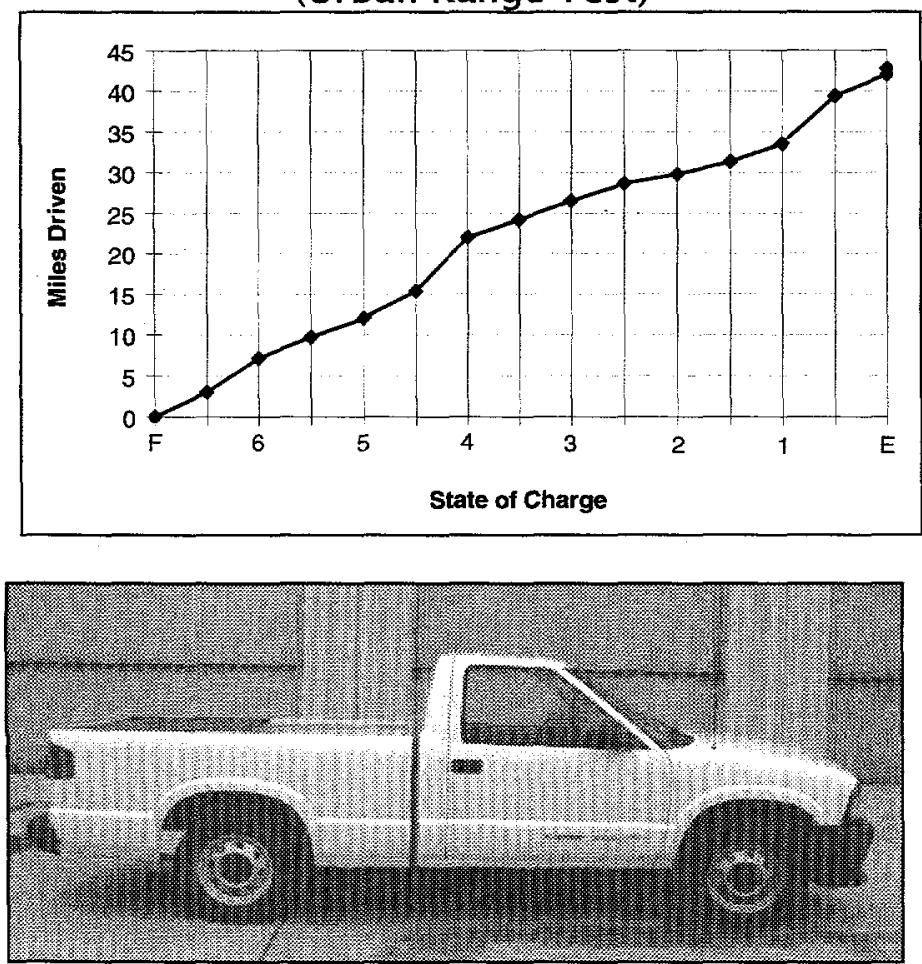

Freeway Range

(ON Freeway POMONa LoOP - SEe OtHer SIDE FOR MAP)
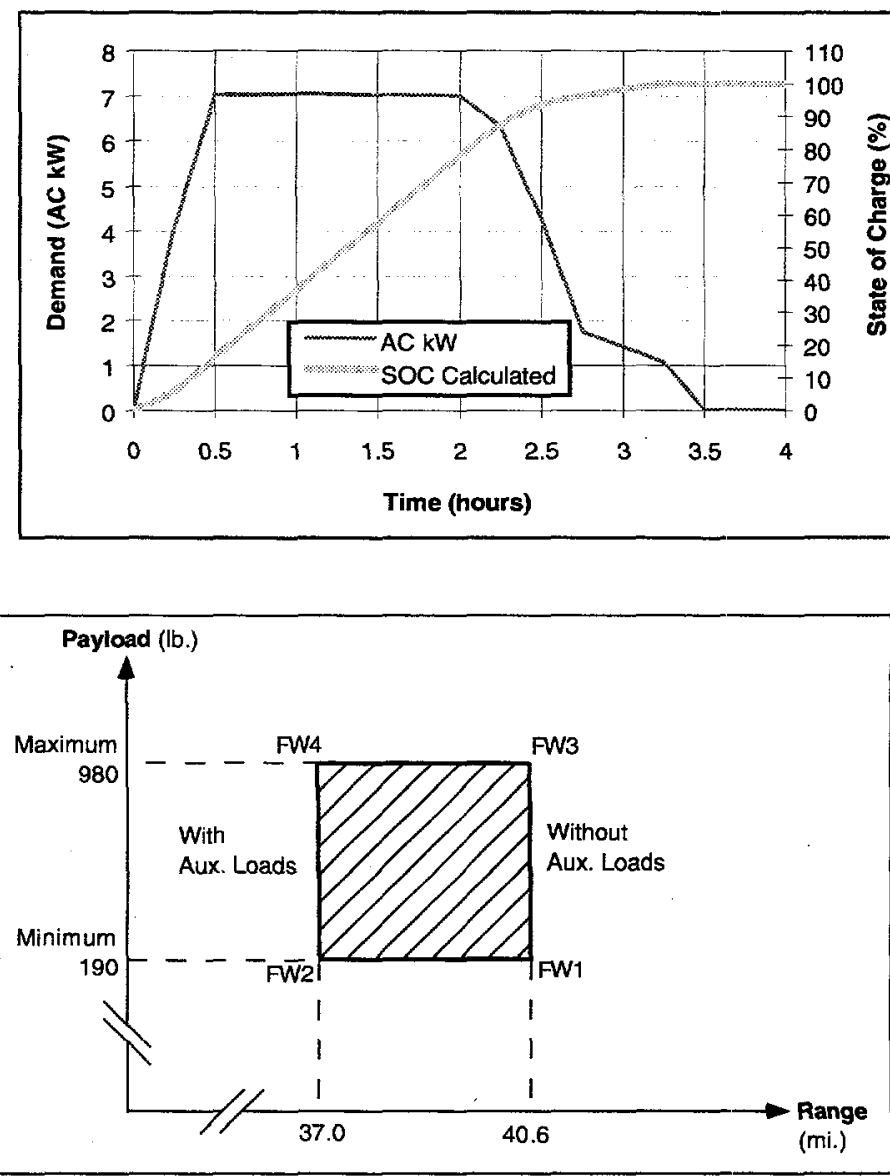

\begin{tabular}{|c|c|c|c|c|}
\hline TEST & FW1 & FW2 & FW3 & FW4 \\
\hline Payload (lb) & 190 & 190 & 980 & 980 \\
\hline AC kWh Recharge & 19.29 & 15.80 & 16.38 & 16.02 \\
\hline AC kWV/mil & 0.475 & 0.427 & 0.403 & 0.433 \\
\hline RANGE $(M)$ ) & 40.6 & 37.0 & 40.6 & 37.0 \\
\hline AVG. AMBIENT TEMP. & $92^{\circ} \mathrm{F}$ & $87^{\circ} \mathrm{F}$ & $83^{\circ} \mathrm{F}$ & $82^{\circ} \mathrm{F}$ \\
\hline
\end{tabular}

\section{Charger}

\begin{tabular}{|c|c|}
\hline 'Measured Value at Peak AC Power \\
\hline Voltage/ Current & $232.3 \mathrm{~V} / 21.71 \mathrm{~A}$ \\
\hline Real Power & $5.013 \mathrm{~kW}$ \\
\hline Reactive/Apparent Power & -481.7 VAR / 5.045 kVA \\
\hline Total/ Displacement Power Factor & $0.99 \mathrm{PF} / 1.00 \mathrm{dPF}$ \\
\hline Voltage THD & $0.4 \%$ \\
\hline Current THD & $4.8 \%$ \\
\hline
\end{tabular}




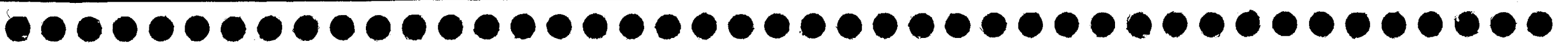
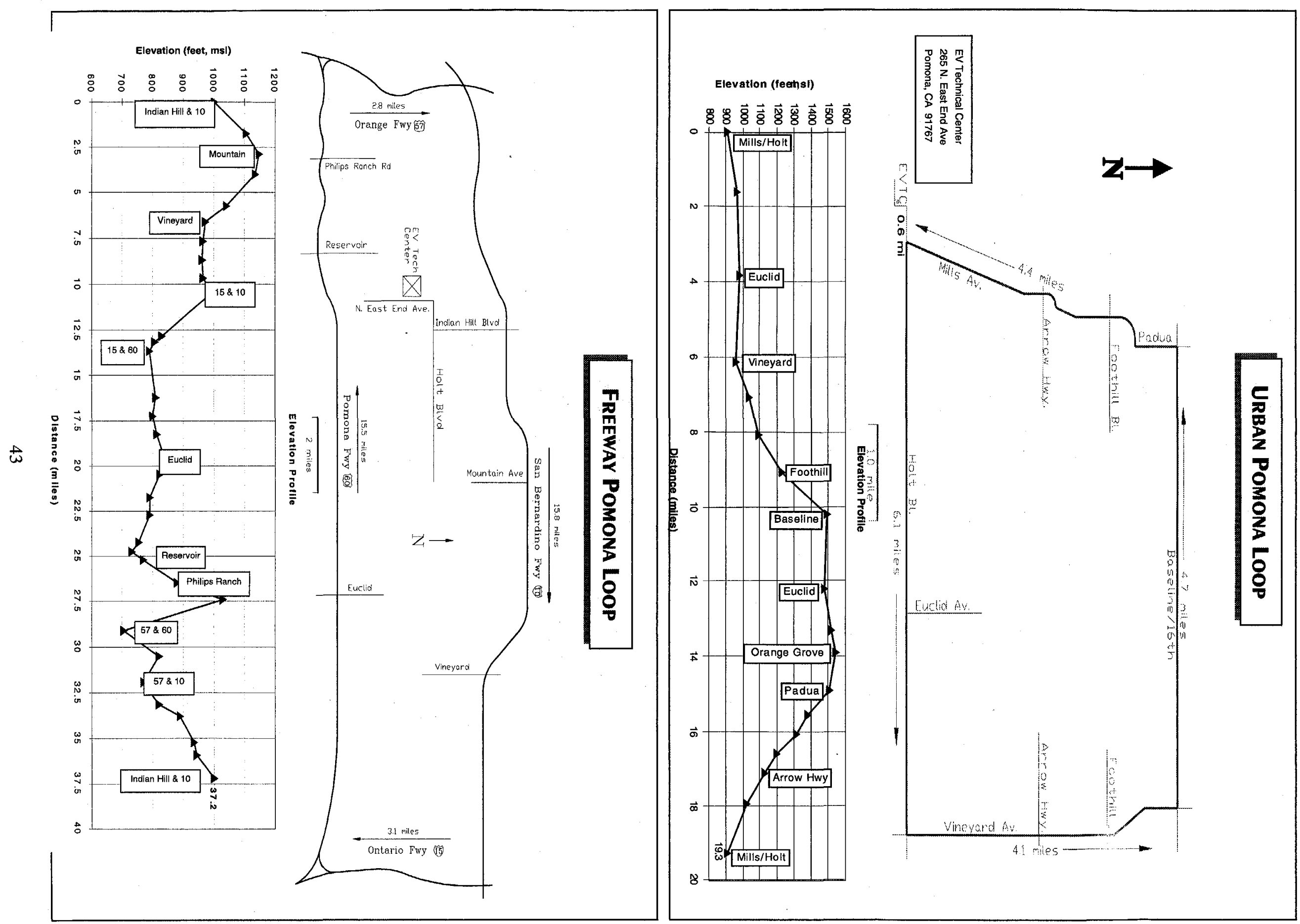